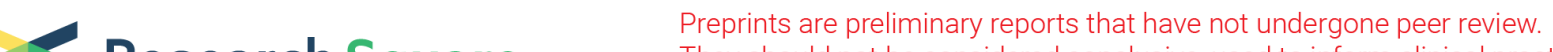 $\begin{array}{ll}\text { Research Square } & \text { They should not be considered conclusive, used to inform clinical practice, } \\ \text { or referenced by the media as validated information. }\end{array}$
}

\section{The peptidyl-prolyl isomerases FKBP15-1 and FKBP15-2 negatively regulate lateral root development by repressing a vacuolar invertase in Arabidopsis}

\section{Jun Wang}

Department of Plant Science, School of Agriculture and Biology, Shanghai Jiao Tong University https://orcid.org/0000-0003-1724-9542

\section{Wenjie Sun}

Department of Plant Science, School of Agriculture and Biology, Shanghai Jiao Tong University Xiuzhen Kong

Department of Plant Science, School of Agriculture and Biology, Shanghai Jiao Tong University Chunyan Zhao

Department of Plant Science, School of Agriculture and Biology, Shanghai Jiao Tong University Jianfu Li

Department of Plant Science, School of Agriculture and Biology, Shanghai Jiao Tong University

\section{Yun Chen}

Department of Plant Science, School of Agriculture and Biology, Shanghai Jiao Tong University

\section{Zhengyin Gao}

Department of Plant Science, School of Agriculture and Biology, Shanghai Jiao Tong University

Kaijing Zuo ( $\sim$ kjzuo@sjtu.edu.cn )

\section{Research article}

Keywords: Arabidopsis, lateral root, FKBP15-1/FKBP15-2, VIN2, sucrose

Posted Date: August 19th, 2019

DOI: https://doi.org/10.21203/rs.2.13125/v1

License: (1) This work is licensed under a Creative Commons Attribution 4.0 International License. Read Full License 


\section{Abstract}

Background Lateral root (LR) architecture determines the efficiency of nutrient absorption and anchors the plant. Internal auxin regulatory mechanisms that control the development of LR have been identified, but how external nutrients influence lateral root development remains elusive. Results We have characterized the functions of the FK506-binding proteins FKBP15-1 and FKBP15-2 in Arabidopsis. FKBP genes are mainly expressed in the vascular bundle of the root basal meristem region, and the FKBP proteins are localized to the endoplasmic reticulum. Co-IP and BIFC assays showed that FKBP15-1 and FKBP15-2 interact with the vacuolar invertase 2 (VIN2). Compared to Col-0 and the single mutants, the double mutant fkbp15-1 fkbp15-2 had more LRs and LR initiation density, and possessed higher sucrose catalytic activity. Moreover, VIN2 can complement the phenotype of increased LRs in the fkbp15-1fkbp152 double mutant. Conclusion Our results indicate that FKBP15-1 and FKBP15-2 together participate in the control of LR numbers by regulating the enzyme activity of VIN2. Due to the activity of peptidylprolyl cistrans isomerases owned by FKBP family proteins, our results provide a clue to further analysis the interplay between lateral root development and protein modification.

\section{Background}

Lateral roots (LRs) are one part of plant root system that function in nutrient and water uptake as well as in physical anchorage [1]. To meet the demands of plant growth and survival, the root system needs to develop a large number of lateral roots to increase root space in the soil [2]. Plants with well-developed lateral root system usually have better nutrient absorption capabilities and higher yields [3].

The development of lateral roots can be divided into at least three distinct phases; lateral roots initiation, the formation of lateral root primordia, and post-emergence growth [4]. Lateral roots initiate from the pericycle cell layer of main root basal meristem area [5]. Some xylem pole-pericycle (XPP) cells in the initiation zone accumulate the maximum amount of auxin and undergo the selection of cell differentiation [6, 7]. Auxin drives the transcriptions of auxin response factor (ARF) genes to control the expressions of GATA transcription factors during establishing the lateral root founder cells [8]. After the first asymmetric division, the divided daughter cells generate a set of short cells called stage I primordium. Cells in stage I divide periclinally to form a two-cell layered primordium. The following developmental stages then give rise to a dome-shaped primordium, and a new lateral root finally emerges from primary root. During these successive developmental processes, auxin induces the specification of the LR primordium through activating ARF7 and ARF19 expressions $[9,10]$. Both ARF7 and ARF19 can be phosphorylated by the brassinosteroid (BR) signal transducer BIN2, and inhibited by ABA [11, 12]. Besides them, cytokinin acts as a negative regulator by regulating auxin synthesis, transport, and signalling to influence LR formation and growth [13]. These results together indicate that the emergence of LRs is a complicated process, which needs the cooperation among different phytohormones. 
Lateral root formation is regulated not only by phytohormones but also by environmental factors [14]. CYTOKININ RESPONSE FACTOR2(CRF) CRF2/ CRF3 function in the LRs for the adaptation to cold stress, in which oxidative-stress-induced reactive oxygen species (ROS) facilitate LR outgrowth by promoting cell wall remodelling in adjacent tissues [15]. When grown under low-phosphorus conditions, LR numbers increase, and their growth angles from main root become smaller in order to acquire more phosphate from the surrounding soil [16]. LR formation is also regulated by nitrate; nitrate-rich soils repress LR formation, whereas locally sparse nitrate levels promote the emergence of LRs [17]. In addition to nitrogen and phosphate, sugars affect LR formation by changing auxin biosynthesis or signalling [18, 19]. Sugars promote lateral root formation at low concentrations, whereas they become inhibitory factor at higher levels. Increasing the concentration of glucose somewhat increases the number of LRs by regulating the expression of auxin-related genes including biosynthesis, transporter, and receptor genes $[20,21]$, indicating the importance of sugar transporting and metabolism in the development of LRs.

Immunophilins are two evolutionarily unrelated groups of proteins with high affinities for the immunesuppressive drugs FK506 and rapamycin, or cyclosporine A (designated as FKBPs/FK506 binding proteins and cyclophilins, respectively) [22]. Immunophilins with the activity of peptidylprolyl cis-trans isomerase widely distribute across different species [23, 24]. In plants, immunophilins comprise large protein families, and play essential roles in stress response, redox regulation of chloroplast function as well as LR development [25-27]. In tomato, SICyp1 regulates the activities of PIN transporters by affecting their localization in plasma membrane during LR formation [28]. In rice, the cyclophilin protein LRT2 directly regulates the stability of the OsIAA11 protein by changing its cis-trans structure; the Irt2 mutation accumulates a higher level of OsIAA11, which then suppresses auxin-induced lateral root development [29]. FKBP42/TWD1 in Arabidopsis positively modulates ABCB/P-glycoprotein transporter activity in polar auxin transport. The FKBP42/TWD1 mutant displays defects in LR development [30-32]. Taken together, these results indicate that immunophilins participate in LR development mostly by regulating gene expressions related to auxin transporting.

To further analysis the roles of immunophilins in LR development, we investigated the function of FKBP15-1 and FKBP15-2 that are phylogenetically related to FKBP42/TWD1 in Arabidopsis. The results showed that both FKBP15-1 and FKBP15-2 could interact with the vacuolar invertase VIN2. Knocked out FKBP15-1 and FKBP15-2 expressions increased the number of LRs and improved the activities of VIN2, suggesting that both FKBP15-1 and FKBP15-2 are required for LR development via the regulation of VIN2 catalysing activity. Because FKBPs possess the activity of peptidyl prolyl cis-trans isomerase, our findings provide clues for further analysing the relationship between LR development and protein folding. 


\section{Methods}

\section{Plant materials}

Arabidopsis thaliana ecotype Col-0 and the T-DNA insertion mutants in FKBP15-1 and FKBP15-2 were provided by the European Arabidopsis Stock Centre [33]. Due to the limited number of FKBP15-2 mutant, RNA interference (RNAi) plants of $F K B P 15-2$ were also generated. The FKBP15-2 specific coding region was amplified using primers carrying attB sites (Additional file 6: Table S1) and recombined into the pHellsgate12 vector to generate the RNAi construct [34]. The construct was transformed separately into Col-0 and fkbp15-1 plants by the floral-dip method. Transgenic plants were then self-pollinated to obtain $\mathrm{T}_{3}$-generation homozygotes of the $f k b p 15-2$-silenced plants. The $f k b p 15-1 f k b p 15-2$ double mutant and fkbp15-1 fkbp15-2RNAi plants were then used in the functional analyses.

Two vectors carrying the 35S::FKBP15-1-eYFP::NOS and 35S::FKBP15-2-eYFP::NOS protein fusion cassettes were transformed into Agrobacterium tumefaciens strain GV3101. The resulting strains were then used to transform $A$. thaliana Col-0 plants to generate the FKBP15-1 and FKBP15-2 overexpression plants, which were self-pollinated to produce the $\mathrm{T}_{3}$-generation homozygotes.

To generate the triple mutant, a plant homozygous for the vin2 gene mutation (SALK_100813) was crossed with the $f k b p 15-1 f k b p 15-2$ double mutant. After self-pollination of the $\mathrm{F}_{1}$, triple mutant plants (fkbp15-1fkbp15-2vin2) were generated and confirmed by PCR.

\section{RNA extraction and quantitative real-time PCR (qRT-PCR) assays}

The tissues (root, stem, leaf, and flower) sampled from 40-day-old seedlings of the Col-0 wild-type and the different mutants and RNAi lines were ground to powder in liquid nitrogen. Total RNA was isolated using the RNA prep-pure Plant Kit as described by the manufacturer (Tiangen, China). RNA samples were quantified by absorbance at $260 \mathrm{~nm}$ using the Nanodrop spectrophotometer (Thermo Fisher Scientific, USA), and the relative purity was assessed by the $A_{260 / 280}$ ratio. For cDNA synthesis, $1 \mu \mathrm{g}$ samples of total RNA were treated with DNase I to remove contaminating genomic DNA, and then reverse-transcribed into $1^{\text {st }}$-strand cDNA using the PrimeScript RT reagent Kit as directed by the manufacturer (Takara, Japan).

The qRT-PCR assays were performed on a LightCycler 96 system (Roche, Switzerland) using the SYBR Premix Ex-Taq kit (Takara, Japan). The amplification conditions were: an initial denaturation at $95^{\circ} \mathrm{C}$ for $10 \mathrm{~min}$, followed by $15-25 \mathrm{cycles}$ of $95^{\circ} \mathrm{C}$ for $15 \mathrm{sec}, 55^{\circ} \mathrm{C}$ for $15 \mathrm{sec}$, and $72^{\circ} \mathrm{C}$ for $30 \mathrm{sec}$, after which samples were returned to room temperature. mRNA of the housekeeping gene UBQ10 was used as internal control. Relative transcription levels were calculated using the comparative $2^{-\triangle \Delta C T}$ method [35]. All experiments were repeated at least three times for reproducibility. The DNA sequences of all primers are given in Additional file 6: Table S1. 


\section{Expression profile analysis}

To analyse the expression patterns of the FKBP15-1 and FKBP15-2 genes, their promoter regions (1213bp for FKBP15-1 and 1180bp for FKBP15-2) were amplified and inserted into $P C A M B I A 1305$ vector to generate the ProFKBP15-1::GUS:::NOS and ProFKBP15-2::GUS::NOS expression constructs. The constructs were transformed into Col-0 plants, and the transgenic plants were verified by PCR.

GUS activity in the transgenic plants was detected histochemically using a previously-described method [36]. Whole 10-day-old seedlings were incubated in GUS staining solution (100 mM phosphate buffer, $\mathrm{pH}$ 7.0, $0.5 \mathrm{mM} \mathrm{K}_{4} \mathrm{Fe}(\mathrm{CN})_{6}, 0.5 \mathrm{mM} \mathrm{K}_{3} \mathrm{Fe}(\mathrm{CN})_{6}, 10 \mathrm{mM}$ EDTA, 0.1\% Triton X-100, and $2 \mathrm{mM}$ 5-bromo-4-chloro3-indolyl $\rho$-o-glucuronic acid) for two hours at $37^{\circ} \mathrm{C}$ in the dark. The stained samples were washed twice in $70 \%(v / v)$ ethanol then examined and photographed using a light microscope (Olympus BX51, Japan).

To determine the expression patterns of FKBP15-1 and FKBP15-2 in roots in detail, GUS-stained roots were fixed overnight in $1 \%$ glutaraldehyde and $4 \%$ paraformaldehyde $(\mathrm{pH} 7.4)$. The samples were dehydrated in a graded ethanol series and embedded in Technovit 7100 resin (Heraeus Kulzer, Wehrheim, Germany). The embedded samples were cut into $10 \mathrm{~mm}$ sections with a microtome (Leica EM UC7, Germany), and prepared for observation and imaging with a differential interference contrast (DIC) microscope (NIKON 80i, Japan).

\section{Subcellular localization of FKBP proteins and BIFC analysis}

Subcellular localization assays were performed using a previously-described method [37]. Agrobacterium strain GV3101 separately carrying the 35S:::FKBP15-1-eYFP::NOS, 35S::FKBP15-2-eYFP::NOS, and ER marker ER-rk expression constructs were grown at $28^{\circ} \mathrm{C}$ overnight. The ER-rk was created by first inserting ER retaining signal at the $\mathrm{C}$-terminus of the mCherry and subsequently adding the signal peptide of AtWAK2 at the N-terminus. The liquid cultures were collected by centrifugation at 2,000 $\mathrm{g}$ for $10 \mathrm{~min}$, and the pellets were re-suspended in MS medium and adjusted to $\mathrm{OD}_{600}=0.5-0.6$. A final concentration of 200 $\mu \mathrm{M}$ acetosyringone and $10 \mathrm{mM}$ MES ( $\mathrm{pH}$ 5.6) were added, and the bacterial suspensions were kept at room temperature for at least 3 hours without shaking prior to infiltration into $N$. benthamiana leaves. Three days after infiltration, the fluorescence signals in leaf epidermal cells were visualized using a Leica SP5 confocal microscope.

For BiFC assays, full-length FKBP15-1 and FKBP15-2 were fused with C-terminal YFP in the vector pEarleygate202-YC, while full-length VIN2 was cloned into vector pEarleygate201-YN and both were transformed into Agrobacterium strain GV3101. Equal ratio of re-suspended bacterial of FKBP15-1/15-2CYFP and VIN2-nYFP were co-injected into N. benthamiana leaves as described above. Within 48-72 hours, pieces of the transformed leaves were observed with confocal microscope for fluorescent signal. 


\section{Root growth measurements}

To analyse the root phenotypes in Col-0 and the FKBP mutants, seeds were surface-sterilized for 5 min in $10 \%(\mathrm{v} / \mathrm{v})$ sodium hypochlorite and washed five times with sterile water, then placed on $0.5 \times \mathrm{MS}$ agar plates under different treatment conditions. To determine the effects of auxin on root growth, IAA was added to $0.5 \times \mathrm{MS}$ medium at a concentration $5 \mathrm{nM}$ or $50 \mathrm{nM}$. The effects of sugars on root growth were determined by adding sucrose, glucose, and fructose separately to $0.5 \times$ MS medium at different concentrations $(0 \%, 0.5 \%, 1 \%, 2 \%, 3 \%$, and $5 \%)$. Plates were placed vertically in a growth chamber at $22^{\circ} \mathrm{C}$ at a light/dark cycle of $16 / 8 \mathrm{~h}$.

After five days of growth, at least 50 plants in each treatment were examined every day. Root lengths were recorded and photographed. All experiments were repeated at least three times. Statistical differences between the different genotypes were calculated using Student's t-test.

\section{Protein co-immunoprecipitation assays}

To determine which proteins interact with FKBP15-1 and FKBP15-2, we performed protein coimmunoprecipitation assays with an anti-GFP antibody [38]. Roots from 12-day-old FKBP15-1-eYFP and FKBP15-2-eYFP transgenic seedlings were collected and ground to powder in liquid nitrogen. Total proteins were extracted in lysis buffer ( $50 \mathrm{mM}$ Tris-HCl, $150 \mathrm{mM} \mathrm{NaCl}, 1 \mathrm{mM}$ EDTA, $10 \%$ glycerol, pH 7.5, and one complete protease inhibitor cocktail tablet per $25 \mathrm{~mL}$ ). Following gentle shaking at $4^{\circ} \mathrm{C}$ for 30 min, the extraction solutions were centrifuged at $15,000 \times \mathrm{g}$ for $10 \mathrm{~min}$. The supernatants were kept on ice before they were used in immunoprecipitation assay. The anti-GFP antibody (Genescript, China) and protein G Sepharose (GE Healthcare, USA) were first mixed and incubated at $4^{\circ} \mathrm{C}$ for $30 \mathrm{~min}$, and the Sepharose-antibody mixture was then incubated with the supernatant with gentle shaking at $4^{\circ} \mathrm{C}$ for $1 \mathrm{~h}$. The protein G Sepharose was collected by centrifugation (30 sec, 15,000 $\mathrm{xg}$ ) and washed three times before elution with a buffer consisting of $50 \mathrm{mM}$ Tris-HCl, pH 6.8, $50 \mathrm{mM}$ dithiothreitol, 1\% SDS, $1 \mathrm{mM}$ EDTA, $0.005 \%$ bromophenol blue, and $10 \%$ glycerol. The eluted proteins were separated by SDS-PAGE for either silver nitrate gel staining, western blotting, or mass spectrometry analysis.

\section{Protein digestion and LC-MS/MS analysis}

Protein bands excised from the SDS-PAGE gels were destained by incubation in destaining solution (7.5 $\mathrm{mM}$ potassium ferricyanide and $25 \mathrm{mM}$ sodium thiosulfate). The proteins in the gel pieces were reduced by incubation in $10 \mathrm{mM}$ DTT solution at $60^{\circ} \mathrm{C}$ for $20 \mathrm{~min}$, followed by alkylation in a solution of $25 \mathrm{mM}$ IAM at room temperature for $15 \mathrm{~min}$. The gel pieces were treated with trypsin (Promega, Madison, WI) overnight at $37^{\circ} \mathrm{C}$ to digest the proteins. The resulting peptides were extracted with $60 \%$ acetonitrile 
containing $5 \%$ formic acid, dried in a SpeedVac, and were then re-dissolved in $2 \%$ acetonitrile containing $0.1 \%$ formic acid for LC-MS/MS analysis.

Peptides were concentrated with a peptide trap column (Thermo Fisher Scientific, USA), and eluted using a solvent system consisting of solvent A $(99.9 \%$ water, $0.1 \%$ formic acid), and solvent B $(99.9 \%$

acetonitrile, $0.1 \%$ formic acid). The peptides were eluted with a gradient of $2-30 \%$ solvent $B$ for 80 min, $30-$ $80 \%$ solvent $B$ for $10 \mathrm{~min}$, and finally $80 \%$ solvent B for 10 min with a constant flow rate of $250 \mathrm{nl} / \mathrm{min}$ in a C18 capillary column (Thermo fisher Scientific, USA). The eluted ions were analysed on an ESI-Q-TOF mass spectrometer in data dependent acquisition mode (m/z 350-1500). The Source Capillary was set at 2000-2400 v, the flow rate and temperature of the dry gas were $2.0 \mathrm{~L} / \mathrm{min}$ and $150^{\circ} \mathrm{C}$, respectively. The mass spectrometer was set as one full MS scan followed by ten MS/MS scans on the ten most intense ions from the MS spectrum with the dynamic exclusion duration set at $15 \mathrm{~s}$.

Tandem mass spectra were extracted, and the charge state was de-convoluted and de-isotoped using Compass Data Analysis version 4.1 (Bruker Daltonics). The peak list was directly generated from the raw data using a centroid algorithm with peak width set at $0.1 \mathrm{~m} / \mathrm{z}$ and intensity above 100 . No peak smoothing or filter processing was applied. After the charge states were calculated, the de-isotoped peak lists were exported as mgf files for further Mascot searches. Mascot (version 2.4, Matrix Science) was set up to search the database. The following parameters were considered for the searches: peptide mass tolerance was set to $20 \mathrm{ppm}$, fragment mass tolerance was set to $0.05 \mathrm{Da}$, and a maximum of two missed trypsin cleavage sites was chosen. Carbamidomethyl (C) was set as fixed modification, and oxidation (M), was set as variable modifications.

\section{Invertase enzyme activity assays}

To assay invertase activity, total proteins were extracted from the roots of 12-day-old Arabidopsis plants in extraction buffer (50 mM Tris-acetate, $\mathrm{pH}$ 7.5; 10 mM EDTA; 5 mM DTT). The homogenates were directly used for invertase assays following a previously-described method [39], and protein concentrations were determined by the Bradford method. For the invertase assays, $100 \mathrm{mg}$ samples of total proteins were incubated for $30 \mathrm{~min}$ with $1 \%$ sucrose in $50 \mathrm{mM}$ potassium phosphate, $\mathrm{pH} 7.0$, at $37^{\circ} \mathrm{C}$, followed by reacting with DNS reagent $\left(100^{\circ} \mathrm{C}\right.$ for $5 \mathrm{~min}$ ) and reading the absorbance at $540 \mathrm{~nm}$. Tubes without sucrose were used as controls. The initial and final glucose concentrations in each sample were quantified on a calibration curve made with different sucrose concentrations. All experiments were repeated four times.

\section{Results}

Suppressing FKBP15-1 and FKBP15-2 gene expression in Arabidopsis increases the number of lateral roots 
Immunophilin FK506-binding proteins in plants influence central and secondary metabolism, cell cycle, and protein folding during vegetative tissue development $[23,25,28,30]$. To better understand the roles of FK506 binding proteins in Arabidopsis, we chose to study FKBP15-1 and FKBP15-2 because the proteins encoded by these genes have the highest sequence identity (68.4\%) at the amino acid level of all the 32 FKBPs, and also because of their co-expression patterns (accessible through Gene Investigator). We firstly characterized the $f k b p 15-1$ mutant (SALK_035550C) and the $f k b p 15-2$ mutant (SALK_113542). The T-DNA insertion in the $f k b p 15-1$ mutant is located 28 bp upstream of the transcription start site, and the fkbp15-2 mutant harbors a T-DNA insertion in the fourth exon (Fig. 1a). Due to the limited number of knock-out mutant lines available, we also generated a FKBP15-2 gene knock-down line, and used qRTPCR to verify that the expression of FKBP15-2 was specifically reduced in the FKBP15-2RNAi plants (Fig. $1 a, b)$.

To identify the functions of $F K B P 15-1$ and $F K B P 15-2$, we investigated primary root length and the number of LRs in Col-0, fkbp15-1, fkbp15-2, fkbp15-2RNAi, fkbp15-1fkbp15-2, and fkbp15-1fkbp15-2RNAi plants grown on 1/2 MS medium. Compared to Col-0, there was no difference in the number of LRs in the single mutants fkbp15-1, fkbp 15-2, and fkbp15-2RNAi, while the fkbp15-1fkbp15-2 double mutant and the fkbp 15-1fkbp15-2RNAi line showed remarkable increases in the number of LRs by $29 \%$ and $22 \%$, respectively (Fig. 1c, d). Feulgen staining indicated that more primordia of LRs were present in the fkbp15-1 fkbp15-2 and fkbp15-1fkbp15-2RNAilines compared with Col-0 (Fig. 2). When grown on 1/2 MS medium for 12 days, the $f k b p 15-1 f k b p 15-2$ and $f k b p 15-1 f k b p 15-2 R N A i$ lines had higher fresh weights with more LRs, but there were no obvious differences in the lengths of the primary roots (Fig. 1d, e, Additional file 1: Figure S1). These observations demonstrate that FKBP15-1 and FKBP15-2 cooperatively regulate the development of LRs in Arabidopsis.

To further analysis the functions of FKBP15-1 and FKBP15-2 in LR development, we overexpressed the FKBP15-1 and FKBP15-2 genes in Col-0 and examined their root phenotypes. Contrary to our expectations, the overexpressed plants (overexpressed FKBP15-1, FKBP15-2, or both genes) showed no significant differences in the number of LRs or primary root length compared to the control Col-0 (Additional file 2: Figure S2). This result indicates that increased transcriptional levels of FKBP15-1 and FKBP15-2 in Arabidopsis cannot change the number of LRs and on primary root development.

\section{FKBP15-1 and FKBP15-2 are mainly expressed in the root vascular bundle}

To analysis the spatial-temporal expression patterns of FKBP15-1 and FKBP15-2, the samples from transgenic plants expressing ProFKBP15-1::GUS and ProFKBP15-2::GUS construct were subjected to GUS staining. Histochemical staining revealed that GUS signals were present in the vascular bundles of the cotyledons, leaves, and roots of 10-day-old seedlings, consistent with qRT-PCR results showing that both genes are expressed in all three tissues, with stronger expression occurred in roots (Fig. 3a, d, Additional file 3: Figure S3). In the roots, FKBP15-1 and FKBP15-2 are mainly expressed in the vascular bundles of primary roots (Fig. $3 \mathrm{~g}, \mathrm{~h}$ ), with high levels of expression observed in the basal meristem during LR 
initiation (Fig. 3k, I), and lower expression levels in the root tip, apical meristem, and the maturation region (Fig. 3b-c, e-h). To visualize the expression patterns of FKBP15-1 and FKBP15-2 in detail, we observed the GUS signals in cross-sections of the basal meristem, and found that the FKBP15-1 and FKBP15-2 signals were mainly present in the pericycle, xylem, and phloem (Fig. $3 \mathrm{i}, \mathrm{j}$ ). Overall, these expression profiles showed that FKBP15-1 and FKBP15-2 are mainly expressed in the root vascular bundle, which is probably related to their roles in the initiation of LR primordia.

\section{FKBP15-1 and FKBP15-2 localize in the endoplasmic reticulum}

To determine the subcellular localization of FKBP15-1 and FKBP15-2 proteins, the fusion proteins eYFPFKBP15-1 and eYFP-FKBP15-2 were transiently expressed separately in leaf epidermal cells of $N$. benthamiana. Two days after infiltration, fluorescent signals were distributed on the cell membrane and endoplasmic reticulum (ER). Co-localization analysis indicated that both FKBP15-1-eYFP and FKBP15-2eYFP co-localized strongly with the ER marker ER-rk (Fig. 4; the Pearson correlation coefficients were 0.966 and 0.957 , respectively. The fluorescence intensities of FKBP15-1/FKBP15-2 are identical to that of ER marker) [40]. Due to their co-expression patterns, we further tested the possibility of interactions between FKBP15-1 and FKBP15-2. As shown in Additional file 4: Figure S4, FKBP15-1 interacted with FKBP15-2 in vivo, and the interaction was stronger in the ER and weaker in the cytoplasm. These results implied that the regulation of FKBP15-1 and FKBP15-2 proteins may occur in the ER.

\section{Auxin regulation in lateral root number is unaffected by the transcriptional expression change of $F K B P 15$ - 1 and FKBP15-2}

Auxin is the key phytohormone controlling LR initiation and patterning in Arabidopsis [10,12]. To analysis the effects of auxin LR numbers in the double mutant and fkbp15-1 fkbp15-2RNAi, we added indole-3acetic acid (IAA) in the 1/2 MS medium to final concentration- $0 \mathrm{nM}, 5 \mathrm{nM}$, and $50 \mathrm{nM}$ respectively. When the concentration of IAA was increased, we didn't observe the narrowed difference of LR number between the double mutant, or $f k b p$ 15-1fkbp15-2RNAi, and Col-0 (Fig. 5a, b). The auxin reporter DR5::GFP showed that the GFP signals in the roots of double mutant and Col-0 plants were identical at the same concentration of IAA (Additional file 5: Figure S5a). Moreover, the expressions of FKBP15-1 and FKBP15-2 genes were unchanged in response to auxin treatment (Additional file 5: Figure $55 b$ ). Taken together, these data indicate that knocked-out or knocked-down of both FKBP15-1 and FKBP15-2 expressions does not influence the function of auxin in LR development in Arabidopsis.

FKBP15-1 and FKBP15-2 interact with an invertase protein in Arabidopsis 
To identify protein(s) that interact with FKBP15-1 and FKBP15-2 in Arabidopsis, we used the coimmunoprecipitation method with the GFP antibody to catch the candidate proteins from the roots of transgenic FKBP15-1-eYFP and 15-2-eYFP plants respectively. The pulled proteins were separated by SDS-PAGE, and confirmed by Western blotting (Fig. 6a, b). IP-MS analysis showed that 113 and 80 proteins were characterized as the candidates interacted with FKBP15-1 and FKBP15-2, respectively. Gene Ontology (GO) analysis indicated that 41 overlapped proteins belong to the functions of protein localization, establishment of protein localization, and immune system process $(P \leq 0.01)$, which agreed with protein modify functions possessed by FKBP families (Fig. 6c, Fig. 7a, Additional file 9, Table. S2). KEGG pathway enrichment analysis revealed that the functions of overlapped proteins are related to the pathways of starch and sucrose metabolism, RNA transport, ribosome, and Cyanoamino acid metabolism (P $\leq 0.01$, Fig. 7b, http://kobas.cbi.pku.edu.cn/annotate.php) [41]. Based on P-values and the number of proteins appeared in the immune-precipitated proteins, the vacuolar invertase (VIN2) and two glucosidases (BGLU22 and BGLU23, glycosyl hydrolase superfamily) ranked the top three proteins (Additional file 6: Figure S6).

In plants, vacuolar invertase acts as a key modulator of hexose accumulation and cell expansion [42-44]. To analyse the interactions between FKBPs and the invertase, we coexpressed the FKBPs with VIN2 in the epidermis cells of tobacco leaf. As shown in Fig 8a-b, the FKBPs could interact with VIN2, and intense fluorescence signals were observed in the ER of epidermis cells. This result implies that the FKBP15-1 and FKBP15-2 proteins together interact with the invertase to regulate sucrose metabolism during LR development.

\section{FKBP15-1 and FKBP15-2 repress lateral root development by negatively regulating the activity of a vacuolar invertase}

To analyse the effects of FKBP15-1 and FKBP15-2 expression on the activity of vacuolar invertase, we compared vacuolar invertase activity in Col-0 with double mutant. Compared with Col-0, the vacuolar invertase activity in the roots of $f k b p 15-1 f k b p 15-2$ plants increased by about $39 \%$, whereas the insignificant difference was observed in leaves (Fig. 8c). This result indicates that knocked-out both FKBP15-1 and FKBP15-2 gene expressions increases the activity of vacuolar invertase mainly in roots.

To identify whether carbon resources influence LR development, we investigated the LR number of fkbp15-1 fkbp15-2 and Col-0 plants in the medium with different kinds of sugars. When the plants grew in the $1 / 2$ MS medium added with $1 \%-5 \%$ sucrose, the differences in the number of LRs between the double mutant and Col-0 were significant (Fig. 8d). When sucrose in the medium was replaced by glucose or fructose, we observed no significant differences in the number of LRs (Fig. 8e, f). Given that the sucrose catalysing ability of invertases and the greater demand for glucose in expanding cells, these results indicated that FKBP15-1 and FKBP15-2 cooperatively repress the development of LRs in a sugardependent manner. 


\section{VIN2 complement the increased lateral root number in the fkbp15-1fkbp15-2 double mutant}

To investigate the genetic relationship between FKBP15-1/FKBP15-2 and VIN2, we generated the triple mutant fkbp15-1fkbp15-2vin2, and determined the LR phenotype (Additional file 7: Figure S7). The results showed that the number of LRs in the triple mutant showed no significant difference compared with Col0 , but was less than that in fkbp15-1fkbp15-2 double mutant (Fig. 9 a, b). No difference in fresh weight and main root length were either observed between fkbp15-1fkbp15-2vin2, and Col-0 (Fig. 9 c-d). These results indicate that VIN2 can complement the mutation of fkbp15-1fkbp15-2, and that VIN2 activity is required for LR development.

\section{Discussion}

Plant immunophilins function in lateral root development mostly by regulating auxin transport and signal transduction [28-32]. Unlike reported functions of immunophilin in LR development, we show here that FKBP15-1 and FKBP15-2 negatively regulate LR number by interacting with a vacuolar invertase VIN2 in Arabidopsis. Analysis of gene spatial expression and protein subcellular localization showed that both FKBP15-1 and FKBP15-2 localize in the ER, an organelle that plays an important role in protein sorting and folding. Given that FKBP family proteins possess peptidylprolyl cis-trans isomerase activity [23-25], these results suggest that both FKBP15-1 and FKBP15-2 proteins may modify the cis-trans conformation of VIN2, and then indirectly change its catalysing activity. In vitro and in vivo analysis showed that the catalytic activity of VIN2 was higher in the control, but repressed in the presence of FKBP15-1 and FKBP15-2 proteins. Although the mechanism how FKBPs change the cis-trans conformation of VIN2 needs to be determined, these results together support that FKBP15-1 and FKBP15-2 regulate the number of LRs probably by changing the conformation of VIN2 during LR initiation.

Sugars influence LR development mainly in two ways: (1) Sugars stimulate LR formation by promoting auxin biosynthesis $[18,45]$. In this study, FKBP15-1 and FKBP15-2 gene expressions were unchanged upon auxin treatment (Fig. S5). Analysis of auxin reporter DR5::GFP further showed that auxin accumulated in LRs and main root were unaffected by the change of FKBP15-1 and FKBP15-2 expressions (Fig. S5). Moreover, improving auxin concentration in 1/2 MS medium didn't narrow the difference in LR number between fkbp15-1fkbp15-2 and Col-0 (Fig. 8). These results together imply that the regulation of FKBP15-1 and FKBP15-2 in LR development is probably independent of the auxintransducing pathway in Arabidopsis; (2) High concentrations of sugars may influence LR development by activating ROS production or improving osmotic pressure [46, 47]. Given that VIN2 is coexpressed with FKBP15-1/15-2 in pericycle founder cells of the basal meristem region, we deduced that repressed VIN2 activity probably decrease sugar supply in the LR primordia, and in turn results in fewer initiation cells in the wild type. In support of this hypothesis, feulgen staining indicated that the number of LR initiation sites were increased in the fkbp15-1 fkbp15-2 mutant. When FKBP15-1FKBP15-2 expression were 
repressed in the double mutant, VIN2 enzyme activity was increased, and more sucrose are likely to be catalysed into glucose (Glc) and fructose (Fru) that promote the emergence of lateral root primordia [48, 49]. Interestingly, two $\beta-1,3$ glucanases were recently identified that localized in the plasmodesma; they can regulate callose accumulation, cell-to-cell connectivity, and the number of lateral roots [50]. Both of these $\beta-1,3$ glucanases were characterized as the candidates interacted with FKBPs; thus future research is needed to confirm whether these two proteins cooperate with VIN2 to regulate LR initiation. Collectively, this research shows that FKBP15-1 and FKBP15-2 have essential functions of regulating LR development in Arabidopsis. Our findings also provide clues into exploiting the interplay between LR development and protein folding.

\section{Declarations}

\section{Ethics approval and consent to participate}

Not applicable.

\section{Consent for publication}

Not applicable.

\section{Availability of data and materials}

The datasets generated and/or analysed during the current study are not publicly available because we are continuing to mine more data from the datasets. However, they are available from the corresponding author upon reasonable request.

\section{Competing interests}

The authors declare that they have no competing interests.

\section{Funding}

This work was supported by grants from the National Natural Science Foundation of China (31071458), the China Transgenic Program (2016ZX08005-003-003), and the Basic Research Project of MOST in China (973 Project) (2014CB733903). The funders were not involved in the design of the study, the data collection and analysis, and writing the manuscript. 


\section{Authors' contributions}

$\mathrm{KZ}$, and JW designed the experiments; KZ, JW, and WS wrote the manuscript; JW, WS, XK, and CZ performed molecular experiments; JL, YC, and ZG analysed the data.

\section{Acknowledgements}

We thank Dr. Sheng Luan (University of California Berkeley) for kindly providing the overexpression vector.

\section{Abbreviations}

LR: Lateral root; FKBP: FK506-binding proteins; VIN2: Vacuolar invertase 2; BIFC: Bimolecular fluorescence complementation; Co-IP: Coimmunoprecipition; XPP: Xylem pole-pericycle; ARF: auxin response factor; Col-0: Columbia-0; ER: Endoplasmic reticulum; UBQ; Ubiquitin; GUS: ß-glucuronidase; ABA: Abscisic acid; YFP: Yellow fluorescent protein; GFP: Green fluorescent protein; MS: Murashige and Skoog

\section{References}

1. Tian H, De Smet I, Ding Z. Shaping a root system: regulating lateral versus primary root growth. Trends Plant Sci. 2014;19:426-31.

2. McCleery WT, Mohd-Radzman NA, Grieneisen VA. Root branching plasticity: collective decisionmaking results from local and global signalling. Curr Opin Cell Biol. 2017;44:51-8.

3. O. Duque L, Villordon A. Root branching and nutrient efficiency: status and way forward in root and tuber crops. Front Plant Sci. 2019;10:237.

4. Santos Teixeira JA, ten Tusscher KH. The systems biology of lateral root formation: connecting the dots. Mol Plant. 2019: doi.org/10.1016/j.molp.2019.03.015.

5. Lavenus J, Lucas M, Laplaze L, Guyomarc'H S. The dicot root as a model system for studying organogenesis. Methods Mol Biol. 2013;959:45-67.

6. De Smet I. Lateral root initiation: one step at a time. New Phytol. 2012;193:867-73.

7. Morenorisueno MA, Norman JMV, Moreno A, Zhang J, Ahnert SE, Benfey PN. Oscillating gene expression determines competence for periodic Arabidopsis root branching. Science. 2010;329:130611.

8. Yadav SR, Bishopp A, Helariutta Y. Plant development: early events in lateral root initiation. Curr Biol. 2010;20:R843-5. 
9. Malamy JE, Benfey PN. Organization and cell differentiation in lateral roots of Arabidopsis thaliana. Development. 1997;124:33-44.

10. Du Y, Scheres B. Lateral root formation and the multiple roles of auxin. J Exp Bot. 2018;69:155-67.

11. Cho H, Ryu H, Rho S, Hill K, Smith S, Audenaert D, Park J, Han S, Beeckman T, Bennett MJ. A secreted peptide acts on BIN2-mediated phosphorylation of ARFs to potentiate auxin response during lateral root development. Nat Cell Biol. 2014;16:66-76.

12. Fukaki H, Tasaka M. Hormone interactions during lateral root formation. Plant Mol Biol. 2009;69:43749.

13. Jing H, C. Strader L. Interplay of auxin and cytokinin in lateral root development. Int J Mol Med Sci. 2019;20:486.

14. Kellermeier F, Armengaud P, J. Seditas T, Danku J, E. Salt D, Amtmann A. Analysis of the root system architecture of Arabidopsis provides a quantitative readout of crosstalk between nutritional signals. Plant Cell. 2014;26:1480-96.

15. Jeon J, Cho C, Lee MR, Binh NV, Kim J. CYTOKININ RESPONSE FACTOR2 (CRF2) and CRF3 regulate lateral root development in response to cold stress in Arabidopsis. Plant Cell. 2016; 28:1828-43.

16. Bai H, Murali B, Barber $K$, Wolverton C. Low phosphate alters lateral root setpoint angle and gravitropism. Am J Bot. 2013;100: 175-82.

17. Sun $\mathrm{CH}, \mathrm{Yu}$ JQ, Hu DG. Nitrate: A crucial signal during lateral roots development. Front Plant Sci. 2017;8:485.

18. Mishra BS, Singh M, Aggrawal P, Laxmi A. Glucose and auxin signaling interaction in controlling Arabidopsis thaliana seedlings root growth and development. PloS One. 2009;4:e4502.

19. Kong D, Hao Y, Cui H. The WUSCHEL related homeobox protein WOX7 regulates the sugar response of lateral root development in Arabidopsis thaliana. Mol Plant. 2016;9:261-70.

20. Gupta A, Singh M, Laxmi A. Interaction between glucose and brassinosteroid during the regulation of lateral root development in Arabidopsis. Plant Physiol. 2015; 168:307-20.

21. Gupta A, Singh M, Mishra BS, Kushwah S, Laxmi A. Role of glucose in spatial distribution of auxin regulated genes. Plant Signal Behav. 2009;4:862-3.

22. Romano P, He Z, Luan S. Introducing immunophilins. From organ transplantation to plant biology. Plant Physiol. 2004;134:1241-3.

23. Harikishore A, Yoon HS. Immunophilins: structures, mechanisms and ligands. Curr Mol Pharmacol. 2015;9:37-47.

24. Galat A. Peptidylprolyl cis/trans isomerases (immunophilins): biological diversity-targets-functions. Curr Top Med Chem. 2003;3:1315-47.

25. Vasudevan D, Gopalan G, Kumar A, J. Garcia V, Luan S, Swaminathan K. Plant immunophilins: a review of their structure-function relationship. Biochim Biophys Acta. 2015;1850:2145-58.

26. Pogorelko GV, Mokryakova M, Fursova OV, Abdeeva I, Eleonora S. Piruzian, Sergey A. Bruskin. Characterization of three Arabidopsis thaliana immunophilin genes involved in the plant defense 
response against Pseudomonas syringae. Gene. 2014;538:12-22.

27. Lima A, Lima S, Wong JH, Phillips RS, Buchanan BB, Luan S. A redox-active FKBP-type immunophilin functions in accumulation of the photosystem II supercomplex in Arabidopsis thaliana. Proc Natl Acad Sci U S A. 2006;103:12631-6.

28. Ivanchenko MG, Zhu J, Wang B, Medvecká E, Du Y, Azzarello E, Mancuso S, Megraw M, Filichkin S, Dubrovsky JG, et al. The cyclophilin A DIAGEOTROPICA gene affects auxin transport in both root and shoot to control lateral root formation. Development. 2015;142:712-21.

29. Jing H, Yang X, Zhang J, Liu X, Zheng H, Dong G, Nian J, Feng J, Xia B, Qian Q, et al. Peptidyl-prolyl isomerization targets rice Aux/IAAs for proteasomal degradation during auxin signalling. Nat Commun. 2015;6:7395.

30. Geisler M, Girin M, Brandt S, Vincenzetti V, Plaza S, Paris N, Kobae Y, Maeshima M, Billion K, Kolukisaoglu UH, et al. Arabidopsis immunophilin-like TWD1 functionally interacts with vacuolar ABC transporters. Mol Biol Cell. 2013;25:202-14.

31. Bouchard R, Bailly A, Blakeslee JJ, Oehring SC, Vincenzetti V, Lee OR, Paponov I, Palme K, Mancuso $S$, Murphy AS, et al. Immunophilin-like TWISTED DWARF1 modulates auxin efflux activities of Arabidopsis P-glycoproteins. J Biol Chem. 2006;281:30603-12.

32. Wang B, Bailly A, Zwiewka M, Henrichs S, Azzarello E, Mancuso S, Maeshima M, Friml J, Schulz A, Geisler M. Arabidopsis TWISTED DWARF1 functionally interacts with auxin exporter ABCB1 on the root plasma membrane. Plant Cell. 2013;25:202-14.

33. Alonso JM, Stepanova AN, Leisse TJ, Kim CJ, Chen H, Shinn P, Stevenson DK, Zimmerman J, Barajas $\mathrm{P}$, Cheuk R, et al. Genome-wide insertional mutagenesis of Arabidopsis thaliana. Science. 2003;301:653-7.

34. Helliwell C, Waterhouse P. Constructs and methods for high-throughput gene silencing in plants. Methods. 2003;30:289-95.

35. Schmittgen TD, Livak KJ. Analyzing real-time PCR data by the comparative $\mathrm{C}_{\mathrm{T}}$ method. Nat Protoc. 2008;3:1101-8.

36. Jefferson RA, Kavanagh TA, Bevan MW. GUS fusions: beta-glucuronidase as a sensitive and versatile gene fusion marker in higher plants. EMBO J. 1987;6:3901-7.

37. Zheng L, Liu G, Meng X, Li Y, Wang Y. A versatile agrobacterium-mediated transient gene expression system for herbaceous plants and trees. Biochem Genet. 2012;50:761-9.

38. Mogami J, Fujita Y, Yoshida T, Tsukiori Y, Nakagami H, Nomura Y, Fujiwara T, Nishida S, Yanagisawa $\mathrm{S}$, Ishida $\mathrm{T}$, et al. Two distinct families of protein kinases are required for plant growth under high external $\mathrm{Mg}^{2+}$ concentrations in Arabidopsis. Plant Physiol. 2014;55:781-9.

39. Leskow CC, Kamenetzky L, Dominguez PG, Díaz Zirpolo JA, Obata T, Costa H, Martí M, Taboga O, Keurentjes J, Sulpice R, et al. Allelic differences in a vaculoar invertase affect Arabidopsis growth at early plant development. J Exp Bot. 2016;67:4091-103. 
40. Nelson BK, Cai X, Nebenführ A. A multicolored set of in vivo organelle markers for co-localization studies in Arabidopsis and other plants. Plant J. 2007;51:1126-36.

41. Xie C, Mao X, Huang J, Ding Y, Wu J, Dong S, Kong L, Gao G, Li CY, Wei L. KOBAS 2.0: a web server for annotation and identification of enriched pathways and diseases. Nucleic Acids Res. 2011;39:316-22.

42. Ruan YL. Sucrose metabolism: gateway to diverse carbon use and sugar signaling. Annu Rev Plant Biol. 2014;65:33-67.

43. Wang L, Li XR, Lian H, Ni DA, He Y, Chen XY, Ruan YL. Evidence that high activity of vacuolar invertase is required for cotton fiber and Arabidopsis root elongation through osmotic dependent and independent pathways, respectively. Plant Physiol. 2010;154:744-56.

44. Morey SR, Hirose T, Hashida Y, Miyao A, Hirochika H, Ohsugi R, Yamagishi J, Aoki N. Genetic Evidence for the Role of a Rice Vacuolar Invertase as a Molecular Sink Strength Determinant. Rice. 2018;11:6.

45. Ljung K, Nemhauser JL, Perata P. New mechanistic links between sugar and hormone signalling networks. Curr Opin Plant Bio. 2015;25:130-7.

46. Manzano C, Pallero-Baena M, Casimiro I, De Rybel B, Orman-Ligeza B, Van Isterdael G, Beeckman T, Draye $\mathrm{X}$, Casero P, Pozo JC. The emerging role of reactive oxygen species signaling during lateral root development. Plant Physiol. 2014;165:1105-19.

47. Couée I, Sulmon C, Gouesbet G, Amrani AE. Involvement of soluble sugars in reactive oxygen species balance and responses to oxidative stress in plants. J Exp Bot. 2006;57:449-59.

48. Yamada K, Osakabe Y, Mizoi J, Nakashima K, Fujita Y, Shinozaki K, Yamaguchi-Shinozaki K. Functional analysis of an Arabidopsis thaliana abiotic stress-inducible facilitated diffusion transporter for monosaccharides. J Biol Chem. 2010;285:1138-46.

49. Somssich M, Khan GA, Persson S. Cell Wall Heterogeneity in Root Development of Arabidopsis. Front Plant Sci. 2016;7:1242.

50. Benitez-Alfonso Y, Faulkner C, Pendle A, Miyashima S, Helariutta Y, Maule A. Symplastic intercellular connectivity regulates lateral root patterning. Dev Cell. 2013;26:136-47.

\section{Figures}


a
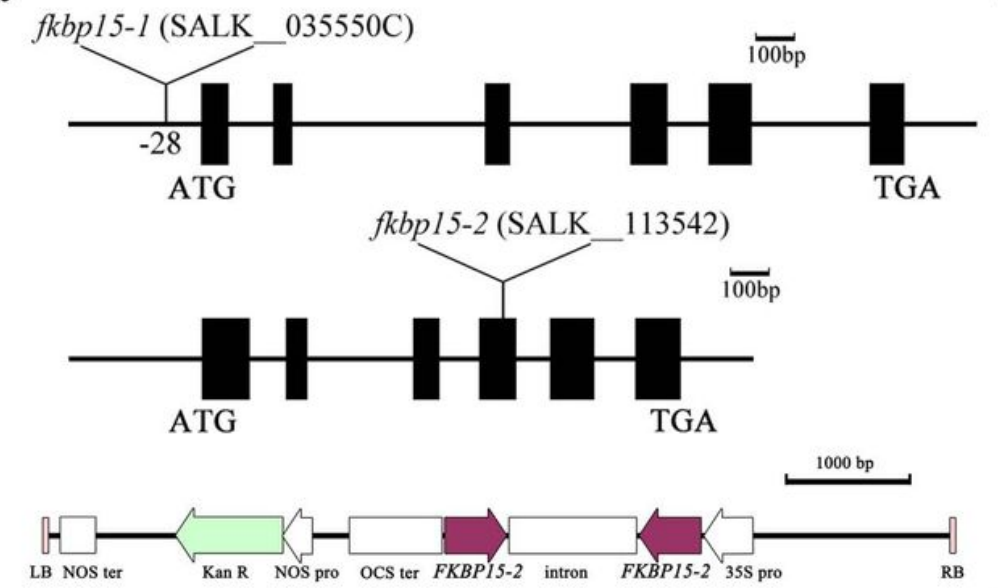

b
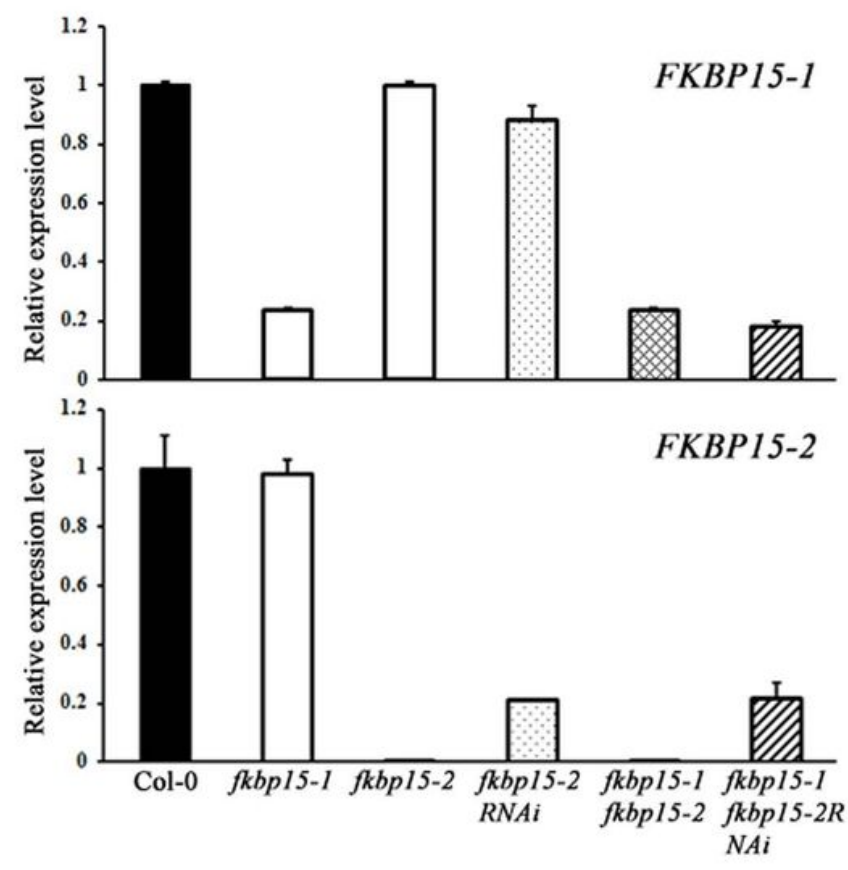

C

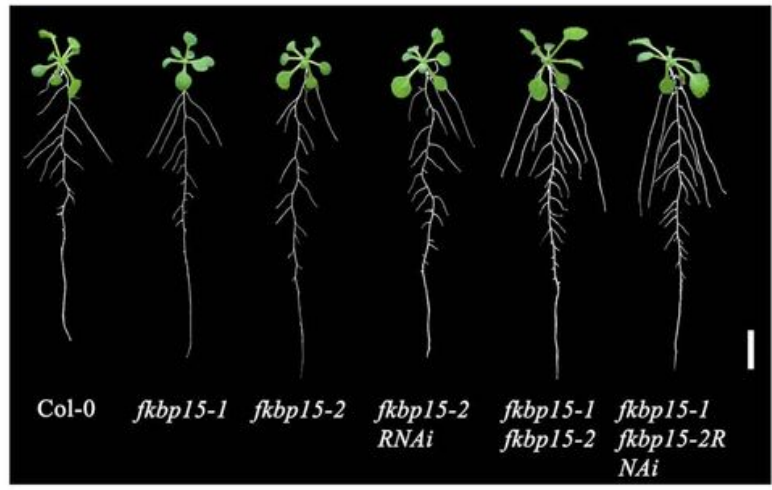

d
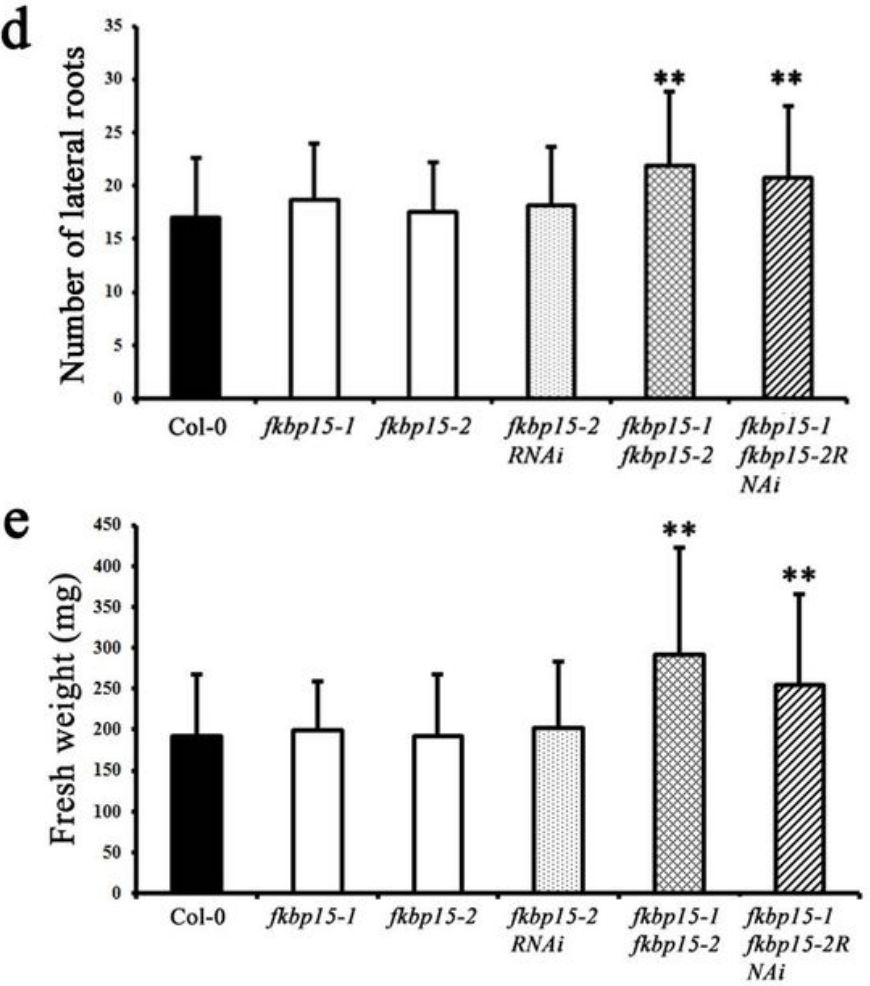

\section{Figure 1}

Suppression of FKBP15-1 and FKBP15-2 gene expression results in an increase in the number of lateral roots in Arabidopsis. a T-DNA insertion positions in the fkbp15-1 and fkbp15-2 mutants and a schematic diagram of the FKBP15-2 RNA interference construct. Black boxes indicate the exons, and the lines between black boxes indicate the introns. $b$ Relative changes in FKBP15-1 and FKBP15-2 transcript levels determined by qRT-PCR analysis in the fkbp15-1, fkbp15-2, fkbp15-2RNAi, fkbp15-1 fkbp15-2, and fkbp15$1 \mathrm{fkbp} 15-2 R N A i$ plants. The UBIQUITIN 10 gene was used as an endogenous control for normalization of gene expression. Error bars represent the SD of the means from three biological replicates. $C$ Representative phenotypes of 12-day-old Col-0, fkbp15-1, fkbp15-2, fkbp15-2RNAi, fkbp15-1fkbp15-2, and fkbp15-1 fkbp15-2RNAi seedlings grown on $0.5 \times M S$ medium. Scale bar: $1 \mathrm{~cm}$. d Determination of the numbers of lateral roots in Col-0, fkbp15-1, fkbp15-2, fkbp15-2RNAi, fkbp15-1 fkbp15-2, and fkbp15$1 \mathrm{fkbp} 15-2 \mathrm{RNAi}$ seedlings. Bars represent average values \pm SD of $\geq 30$ seedlings of each genotype. 
Asterisks indicate significant differences in the number of lateral roots in each genotype compared with Col-0 ( ${ }^{\star} \mathrm{P} \leq 0.05,{ }^{\star} \mathrm{P} \leq 0.01$; Student's t-test). e Determination of fresh weight in Col-0, fkbp15-1, fkbp15-2, fkbp15-2RNAi, fkbp15-1 fkbp15-2, and fkbp15-1fkbp15-2RNAi seedlings. Bars represent average values \pm SD of $\geq 30$ seedlings of each genotype. Asterisks indicate significant differences in fresh weight in each genotype compared with Col-0 (*P $\leq 0.05,{ }^{* *} \mathrm{P} \leq 0.01$; Student's t-test).

a

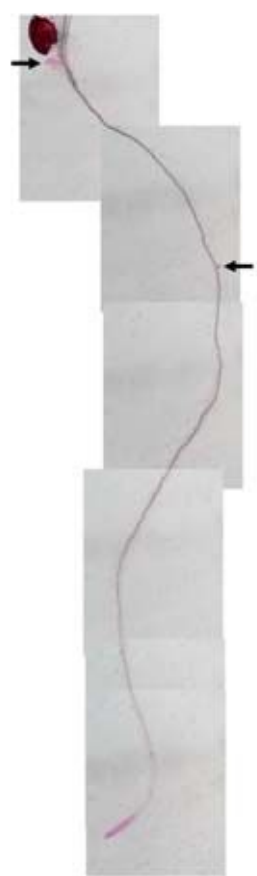

Col-0
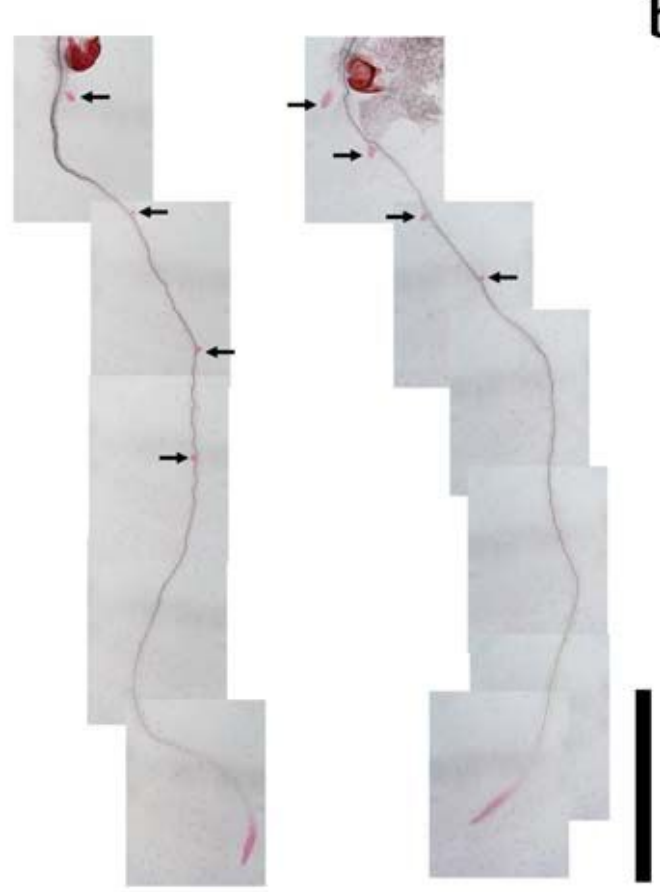

b

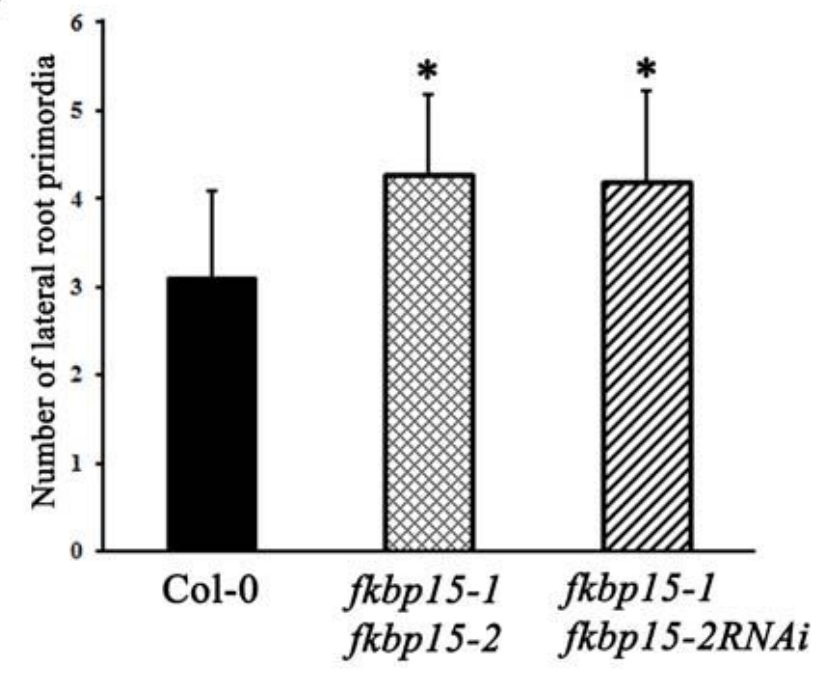

\section{Figure 2}

Suppression of FKBP15-1 and FKBP15-2 gene expression results in an increase in the number of lateral root primordia in Arabidopsis. a Feulgen staining of the lateral root primordia in 5-day-old seedlings of Col-0, fkbp15-1fkbp15-2, and fkbp15-1fkbp15-2RNAi grown on 0.5×MS medium. Scale bar: $5 \mathrm{~mm}$. b Statistical analysis of lateral root primordia numbers in Col-0, fkbp15-1 fkbp15-2, and fkbp15-1fkbp15$2 R N A i$ seedlings. Bars represent average values $\pm S D$ of $\geq 30$ seedlings of each genotype. Asterisks indicate significant differences in the number of lateral root primordia in each genotype compared with Col-0 (*P $\leq 0.05,{ }^{\star *} \mathrm{P} \leq 0.01$; Student's t-test). 

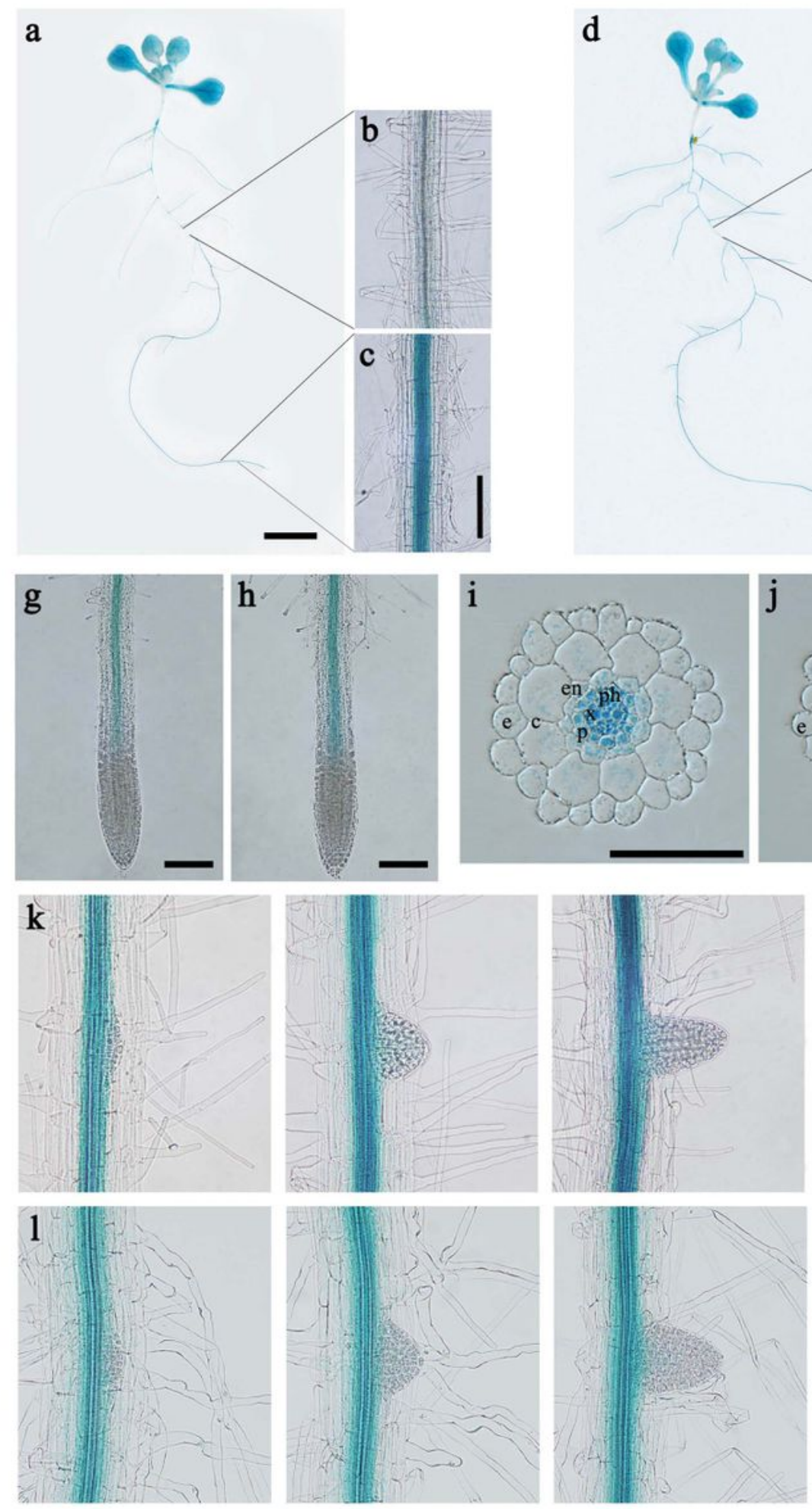
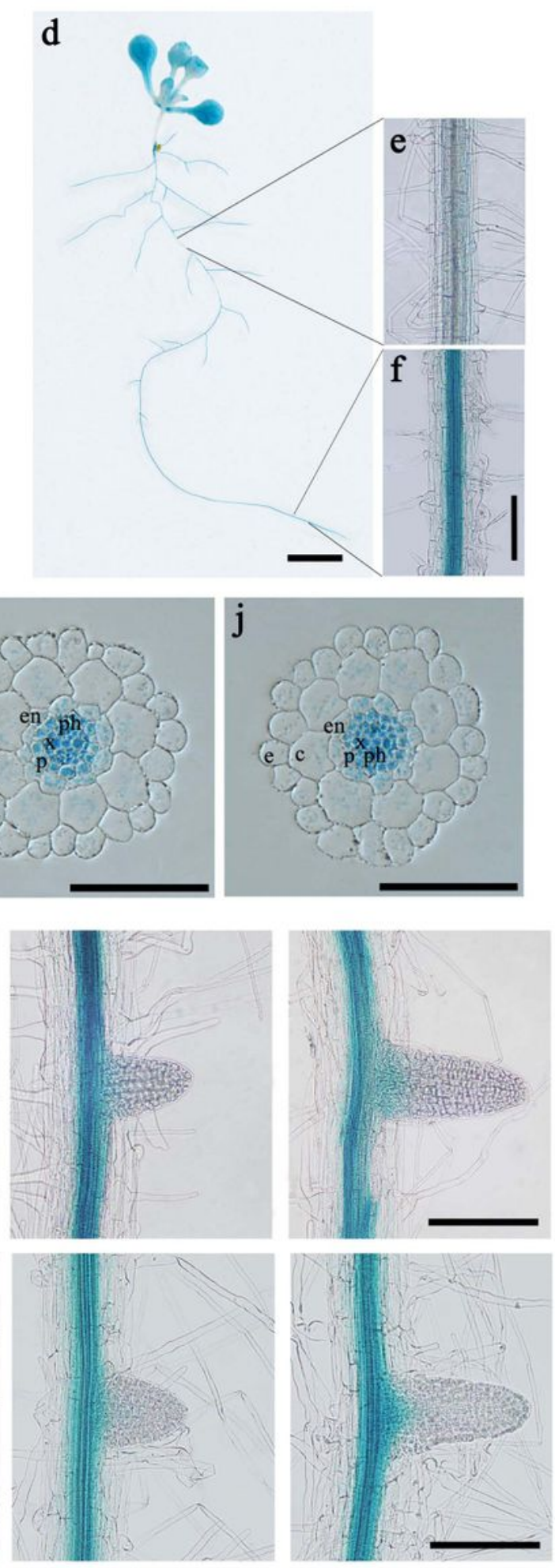

\section{Figure 3}

FKBP15-1 and FKBP15-2 are highly expressed in the vascular system in Arabidopsis. GUS staining of transgenic Arabidopsis seedlings expressing the ProFKBP15-1::GUS::NOS and ProFKBP15-2::GUS::NOS constructs. (a, b, c, g, i, k) ProFKBP15-1::GUS::NOS, (d, e, f, h, j, l) ProFKBP15-2::GUS::NOS. a, d 10-day-old seedlings. The insets show the upper ( $b$ and $e$ ) and lower ( $c$ and $f$ ) main root regions marked in a and $d$, respectively. $\mathrm{g}$, h main root tips in 10-day-old seedlings. $\mathrm{i}$, j cross sections of basal meristems in the main 
root. e, epidermis; c, cortex; en, endodermis; p, pericycle; $x$, xylem; ph, phloem. Scale bar: $100 \square \mathrm{m}$. k, I time course of lateral root development. Scale bars: $5 \mathrm{~mm}$ in a and d; $200 \square \mathrm{m}$ in b, c, e, f, g, h, k, and l; $100 \square \mathrm{m}$ in $\mathrm{i}$ and $\mathrm{j}$.

Dark Field
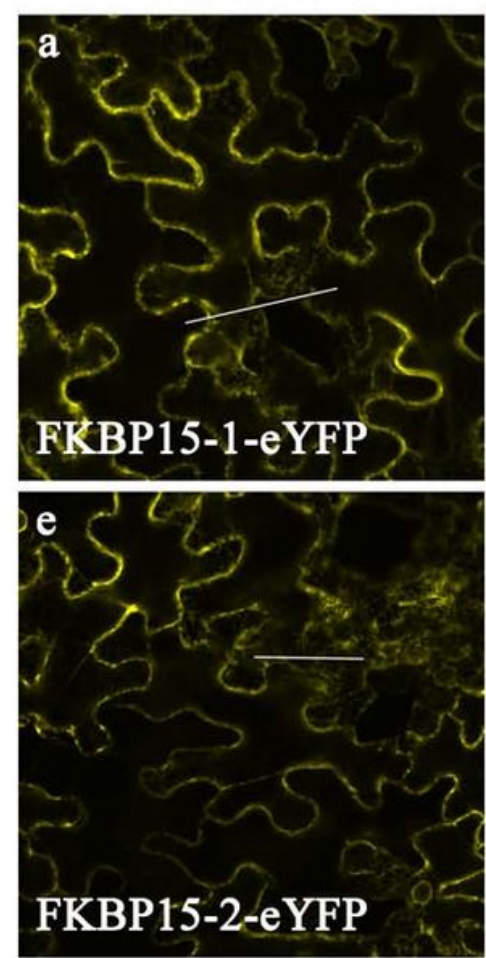

Dark Field

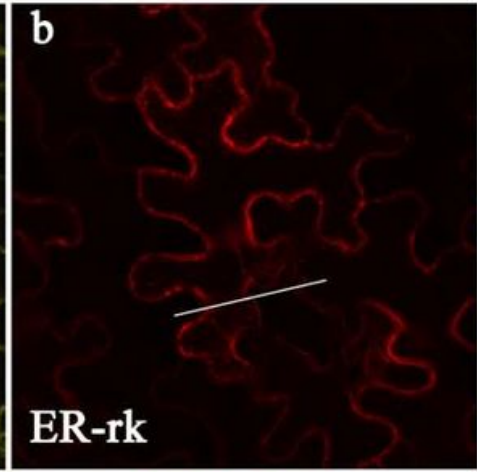

f

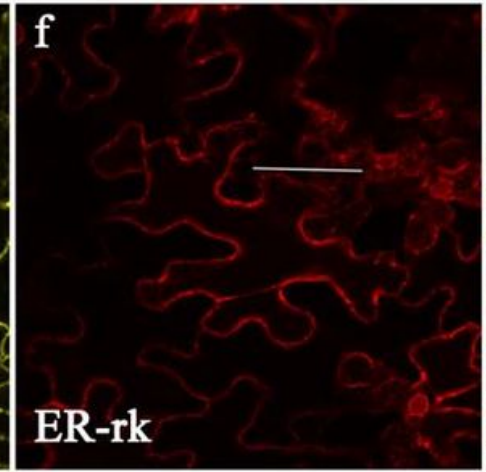

Merge
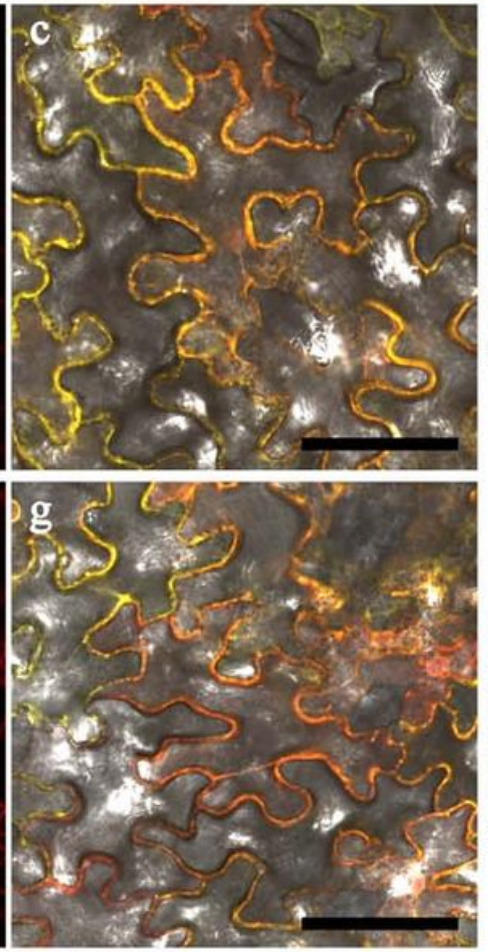

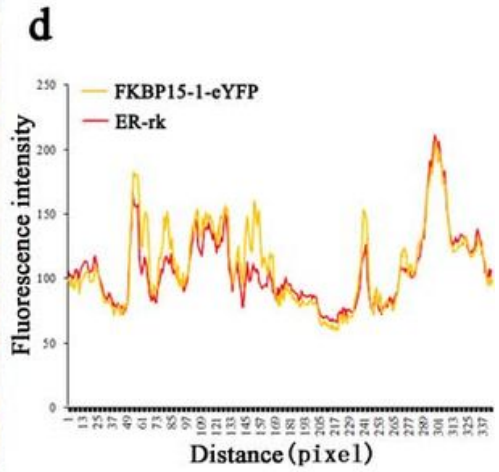

h

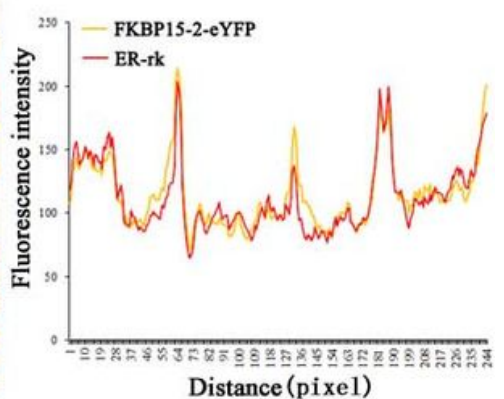

\section{Figure 4}

FKBP15-1 and FBKP15-2 are localized in the ER in N. benthamiana leaf epidermal cells. a-d FKBP15-1eYFP images. Yellow fluorescence of the eYFP fusion protein (a), red fluorescence of the ER marker ER-rk (b), merged image of FKBP15-1-eYFP and the ER marker ER-rk (c) fluorescence intensities of the areas of (a) and (b) indicated by white lines (d). e-h FKBP15-2-eYFP images. Yellow fluorescence of the eYFP fusion protein (e), red fluorescence of ER-rk (f), merged image of FKBP15-2-eYFP and the ER marker ER-rk fluorescence $(\mathrm{g})$ fluorescence intensities of the areas of $(\mathrm{e})$ and $(\mathrm{f})$ indicated by white lines $(\mathrm{h})$. Scale bar: $100 \rrbracket \mathrm{m}$. 

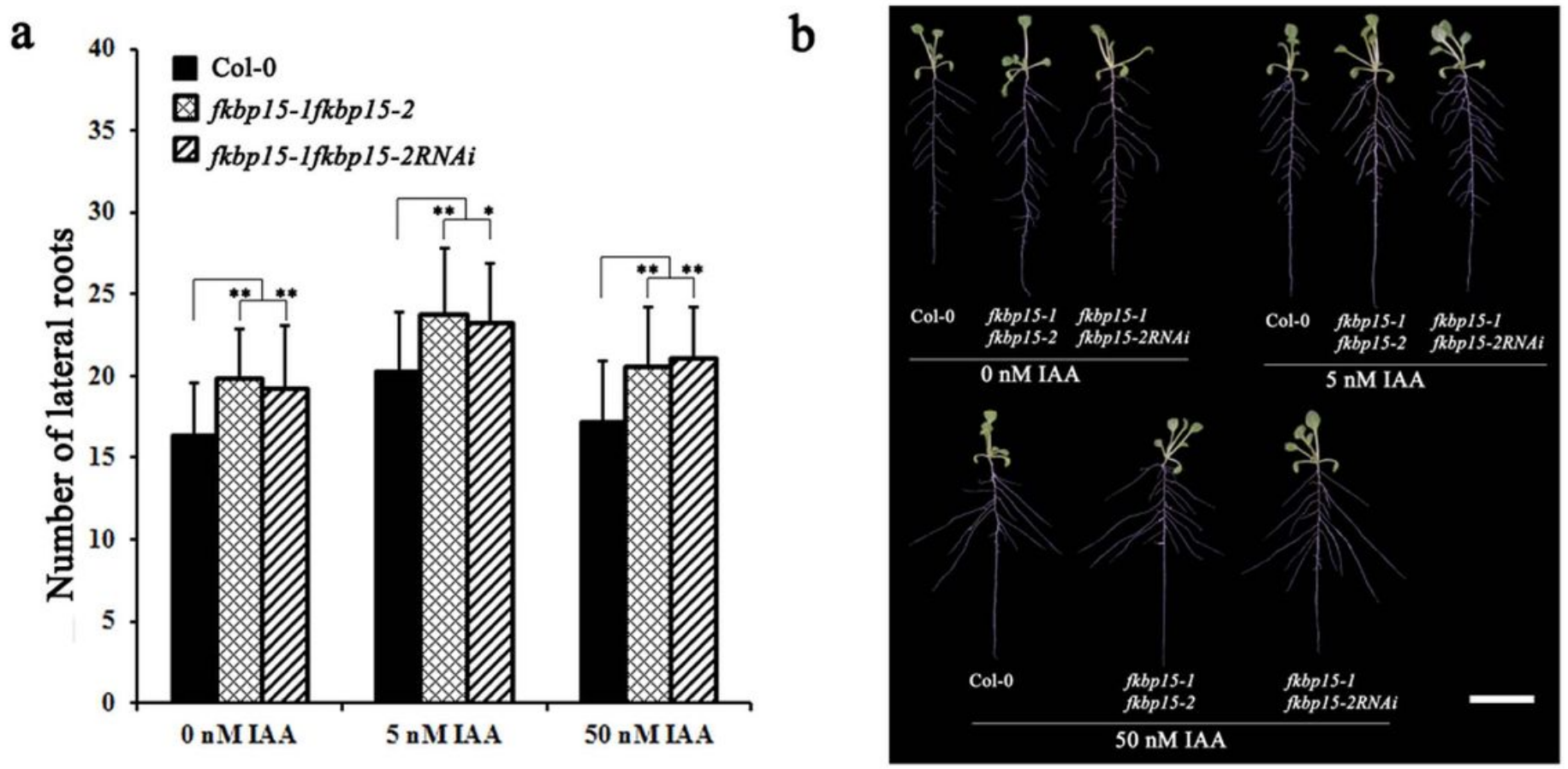

\section{Figure 5}

FKP15-1 and FKBP15-2 control lateral root development in a manner distinct from auxin signaling. a Lateral root number in Col-0, fkbp15-1fkbp15-2, and fkbp15-1 fkbp15-2RNAi seedlings grown on 0.5× MS medium containing $0 \mathrm{nM}$ (only with reagent dissolving the IAA), $5 \mathrm{nM}$, or $50 \mathrm{nM}$ IAA respectively. Bars represent average values $\pm S D$ of $\geq 30$ seedlings of each genotype. Asterisks indicate significant change of lateral root number in each genotype compared with that in Col- 0 ( ${ }^{*} \mathrm{P} \leq 0.05$, ${ }^{\star *} \mathrm{P} \leq 0.01$; Student's $\mathrm{t}$ test). $\mathrm{b}$ Root phenotypes of Col-0, fkbp15-1fkbp15-2, and fkbp15-1 fkbp15-2RNAi seedlings grown on 0.5x MS medium containing $0 \mathrm{nM}, 5 \mathrm{nM}$, or $50 \mathrm{nM}$ IAA. Scale bar: $1 \mathrm{~cm}$. 
a

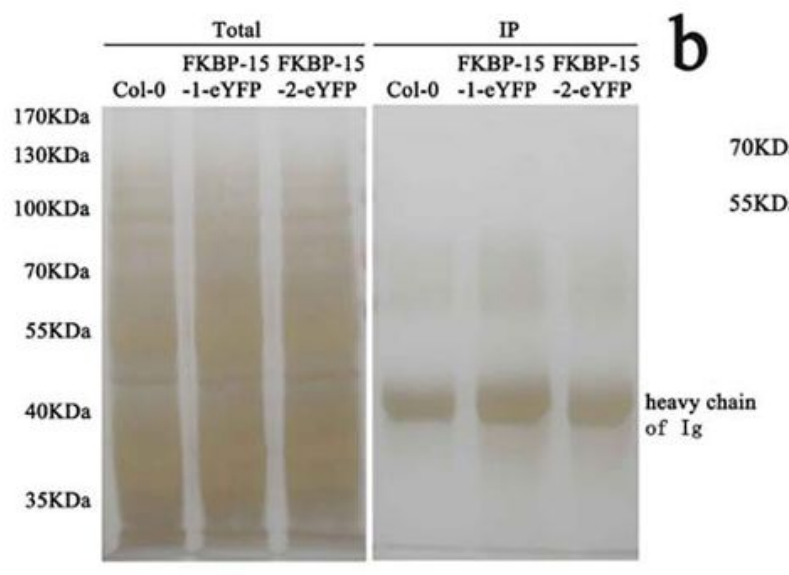

\section{C}

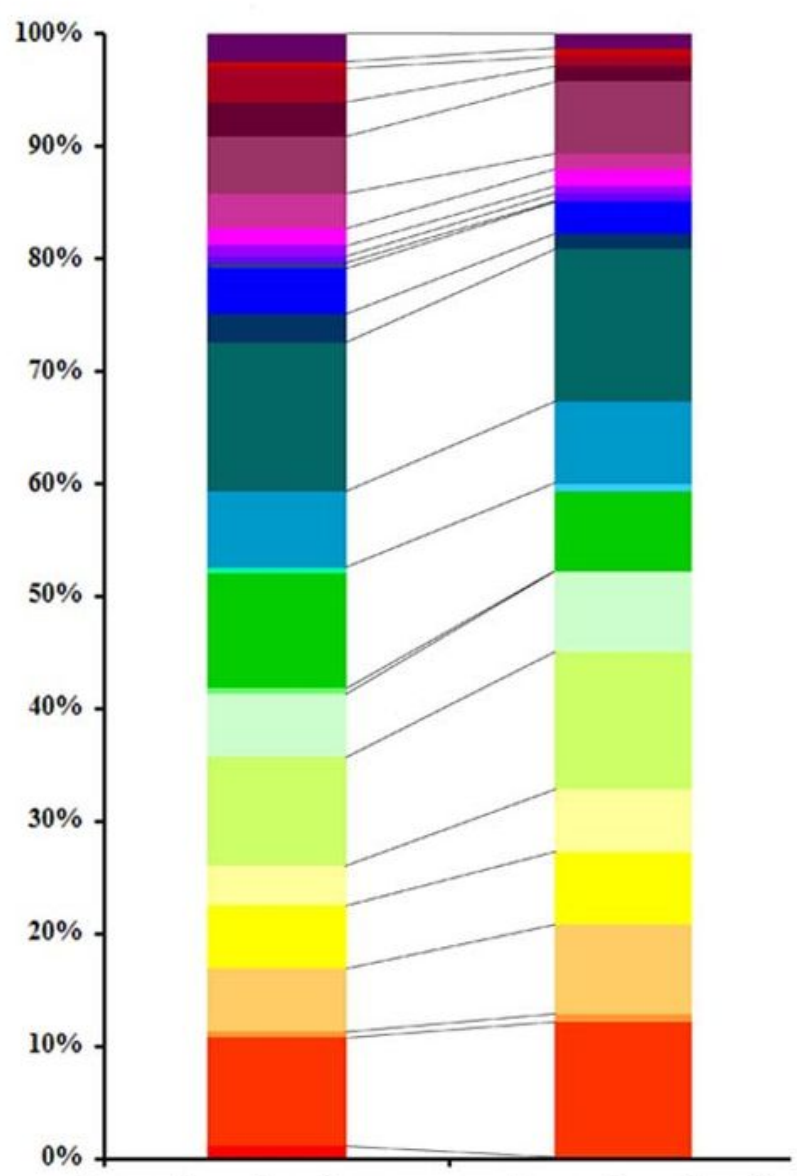

- biological regulation

- multi-organism process

- establishment of localization

- localization

- response to stimulus

- cellular component biogenesis

-pigmentation

- developmental process

- multicellular organismal process

- reproductive process

- cellular component organization

- anatomical structure formation

- cellular process

- metabolic process

=immune system process

- reproduction

- binding

= transporter activity

catalytic activity

cell part

organelle part

organelle

macromolecular complex

membrane-enclosed lumen

- cell

- extracelluar region

Proteins that interact Proteins that interact with FKBP15-1 with FKBP15-2

\section{Figure 6}

Identification and GO (Gene Ontology) annotation of proteins that interact with FKBP15-1 and FKBP15-2 by immunoprecipitation coupled with LC-MS/MS analysis. a, b Samples before and after immunoprecipitation were separated by SDS-PAGE for silver nitrate staining (a) or western blotting analysis using the GFP antibody (b). (c) GO annotation and the enrichment ratios for the proteins pulled down by FKBP15-1-YFP and FKBP15-2-YFP. The y-axis shows the enrichment ratio for the $26 \mathrm{GO}$ terms in 
the three major GO categories "Biological Function", "Cellular Component", and "Molecular Function", and the $x$-axis indicates the proteins that interact with FKBP15-1 and FKBP15-2.

a

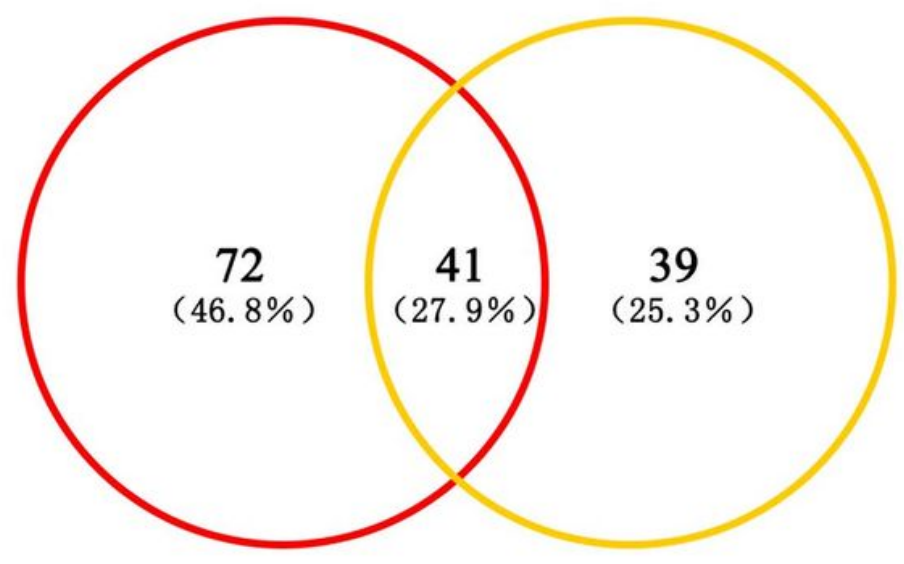

Proteins pulled down by FKBP15-1-YFP

Proteins pulled down

by FKBP15-2-YFP

b

Starch and sucrose metabolism RNA transport RNA degradation Ribosome -

Protein processing in endoplasmic reticulum -

Protein export Phenylpropanoid biosynthesis Phagosome Nitrogen metabolism mRNA surveillance pathway Metabolic pathways Glycolysis / Gluconeogenesis Galactose metabolism Cyanoamino acid metabolism Carbon metabolism Carbon fixation in photosynthetic organisms Biosynthesis of secondary metabolisms Biosynthesis of amino acids Base excision repair Arginine biosynthesis Alanine, aspartate and glutamate metabolism -

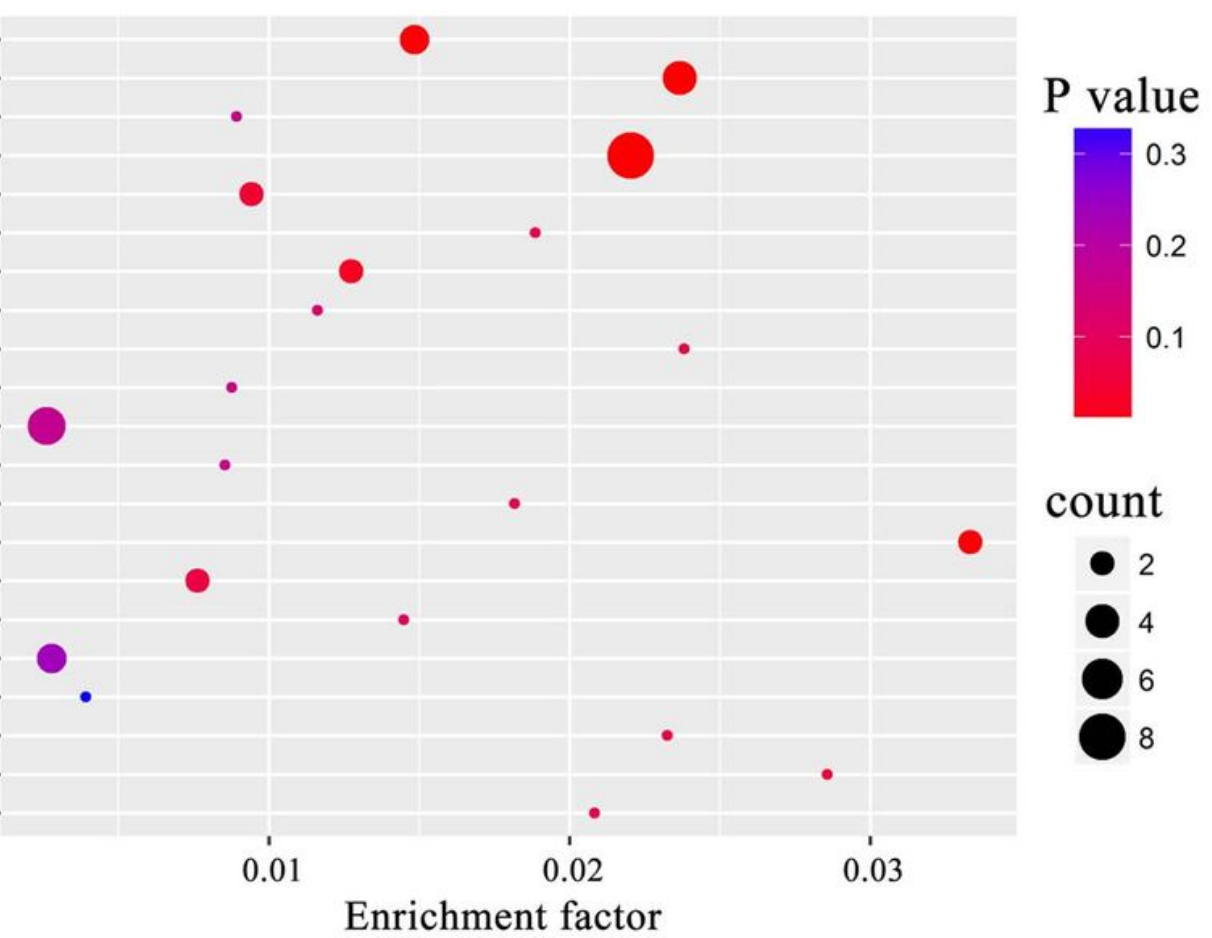

\section{Figure 7}

KEGG pathway enrichment analysis of proteins pulled down by the FKBP15-1-YFP and FKBP15-2-YFP fusion proteins. a Venn diagram showing the unique and shared proteins pulled down by FKBP15-1-YFP and FKBP15-2-YFP. b KEGG pathway enrichment analysis of the proteins pulled down by FKBP15-1-YFP and FKBP15-2-YFP. "count" indicates the number of genes associated with a given pathway in the proteins pulled down by FKBP15-1-YFP and FKBP15-2-YFP. "Enrichment factor" shows the ratio between the count and the number of all proteins in the pathway. 
a

$\begin{array}{rlll}\text { VIN2-mCherry } & + & + & + \\ \text { FKBP15-1-eYFP } & - & + & - \\ \text { FKBP15-2-eYFP } & - & - & +\end{array}$

Anti-mCherry

Anti-eYFP

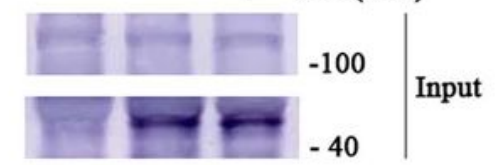

Anti-mCherry

Anti-eYFP

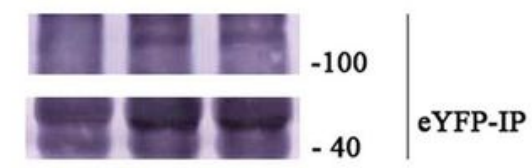

c

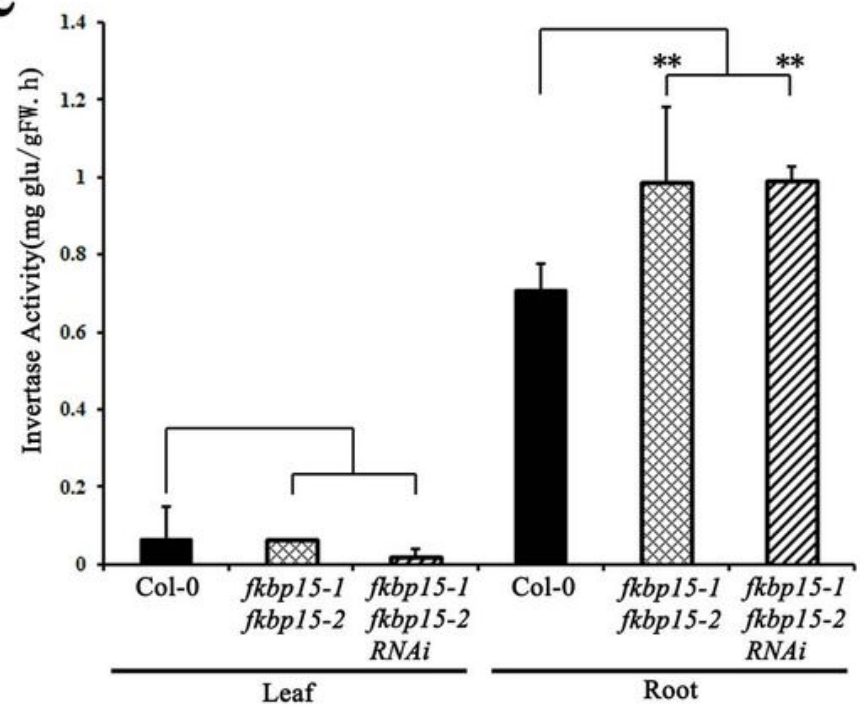

e

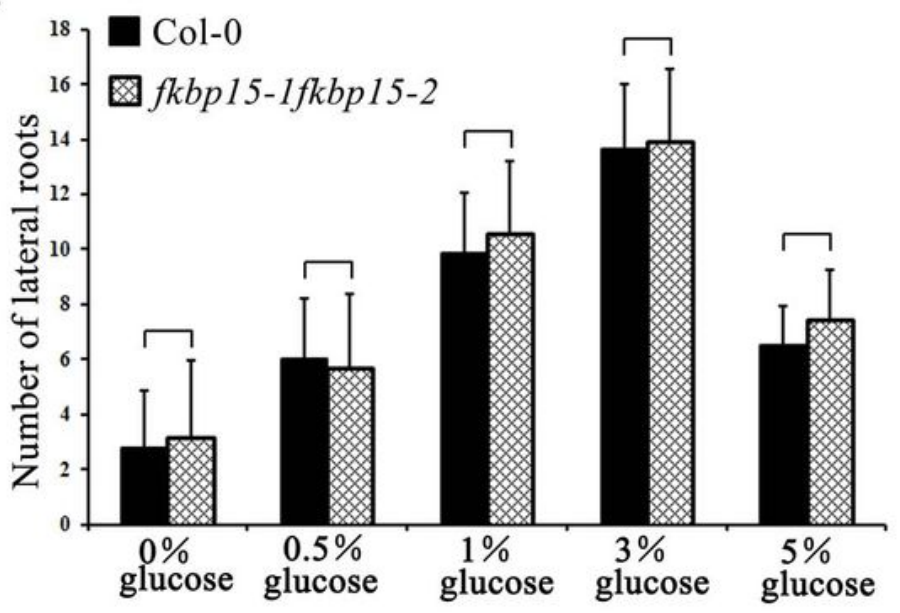

b

FKBP15-1-eYFP-C AtVIN2-eYFP-N
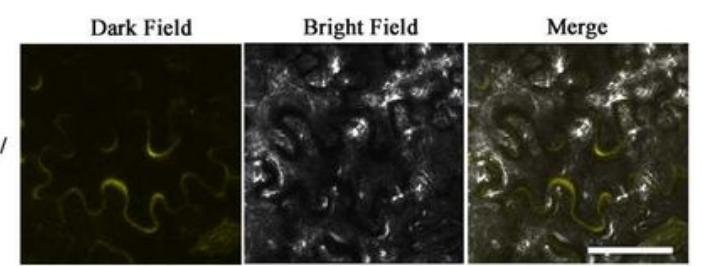

FKBP15-2-eYFP-C/ AtVIN2-eYFP-N

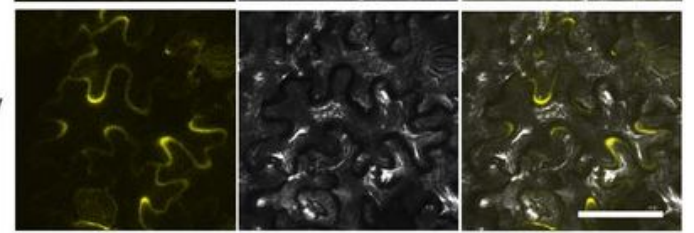

eYFP-C/ AtVIN2-eYFP-N

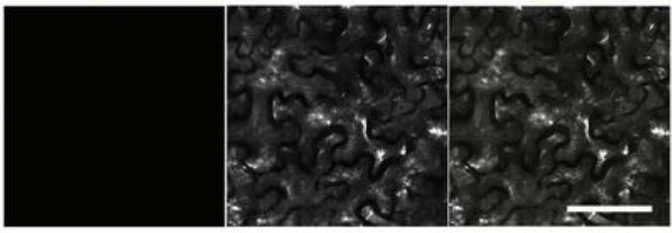

d

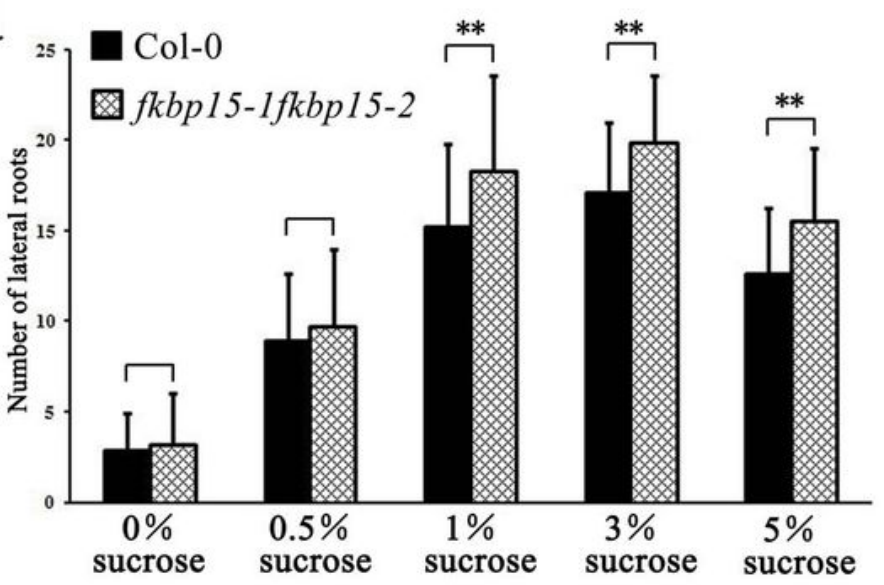

f

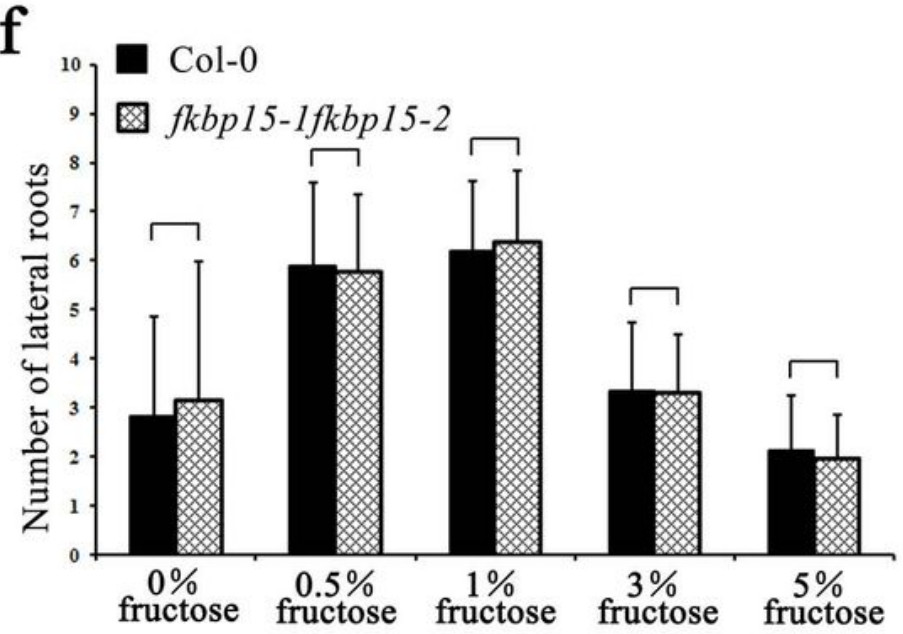

\section{Figure 8}

Analysis of the interactions between FKBP15-1, FKBP15-2 and VIN2, analysis of invertase activity, and sugar utilization efficiency in the fkbp15-1 fkbp15-2 double mutant. a Coimmunoprecipition (Co-IP) of transiently co-expressed VIN2-mCherry, FKBP15-1-eYFP, and FKBP15-2-eYFP in leaves of N. benthamiana. Soluble proteins were extracted before (Input) and after (IP) immunoprecipitation with anti-eYFP antibody-conjugated beads, and the capture proteins were detected by Western blotting with anti-mCherry 
antibody. b BiFC analysis of interactions between FKBP15-1, FKBP15-2, and VIN2. Scale bar: $50 \mathrm{~mm}$. c Invertase activity in Col-0, fkbp15-1 fkbp15-2, fkbp15-1 fkbp15-2RNAi. Bars represent average values $\pm S D$ of $\geq 30$ seedlings of each genotype. Short lines in upper side of column represent which Col-0 is statistical comparison, asterisks (or no asterisk) indicate significant differences (or no significant differences) in lateral root number in each genotype compared with Col-0 (*P $\leq 0.05, * * P \leq 0.01$, by Student's t-test). $d, e, f$ Lateral root numbers in fkbp15-1 fkbp15-2 seedlings grown on $0.5 \times$ MS medium with final concentrations $(0.5,1,3$, and $5 \%$ respectively) of sucrose (d), glucose (e), and fructose (f). Bars represent average values $\pm S D$ of $\geq 30$ seedlings. Short lines in upper side of column represent which Col-0 is statistical comparison, asterisks (or no asterisk) indicate significant differences (or no significant differences) in lateral root number in each genotype compared with Col-0 (*P $\leq 0.05, * * P \leq 0.01$, by Student's t-test). 
a

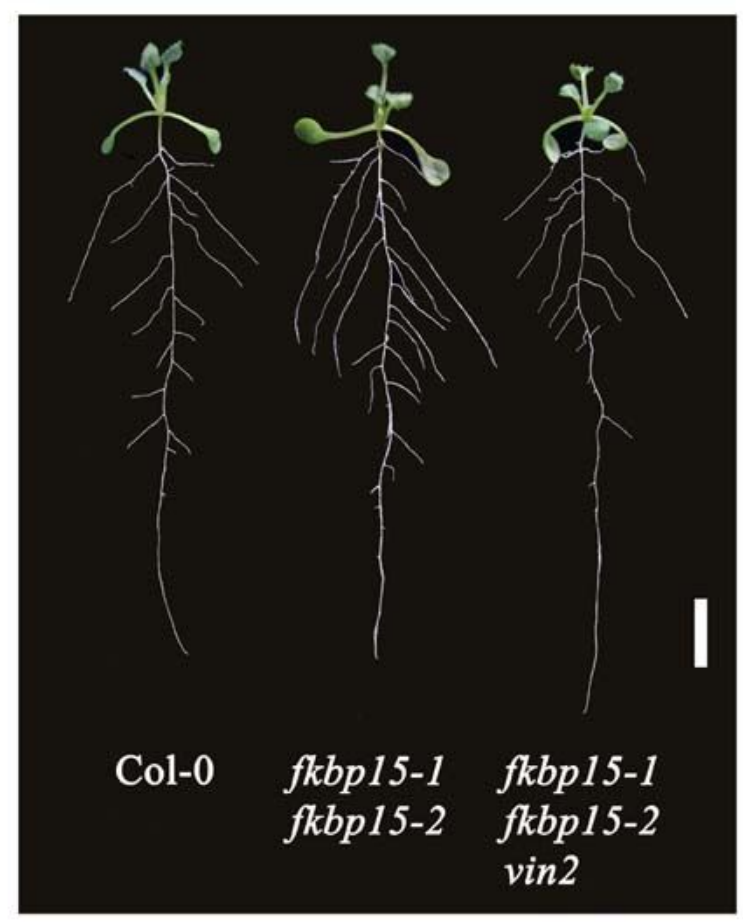

C

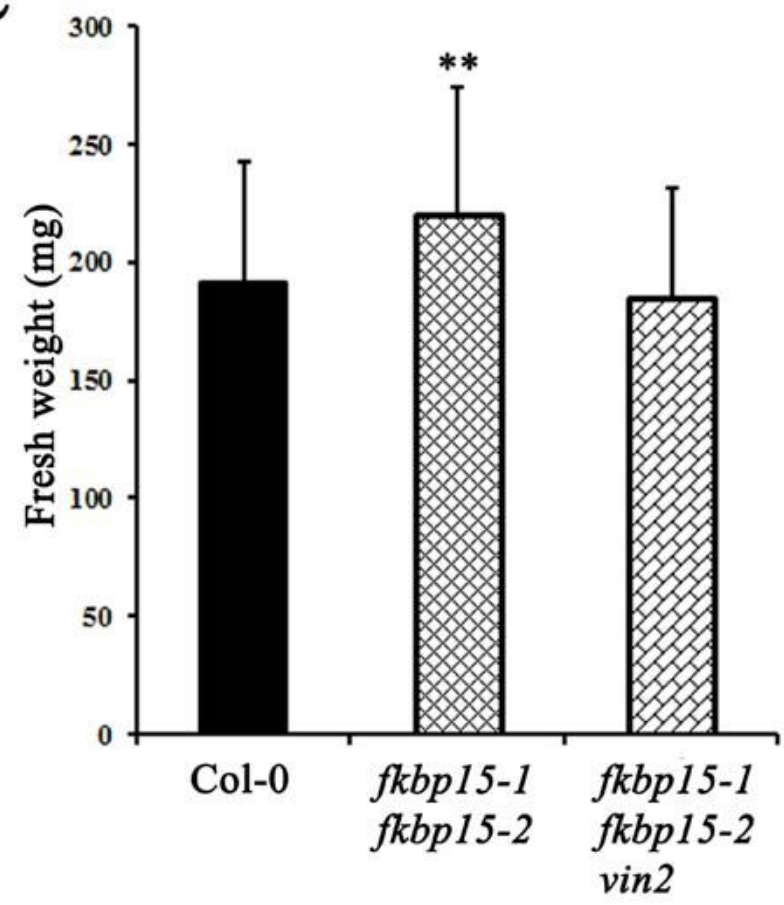

b

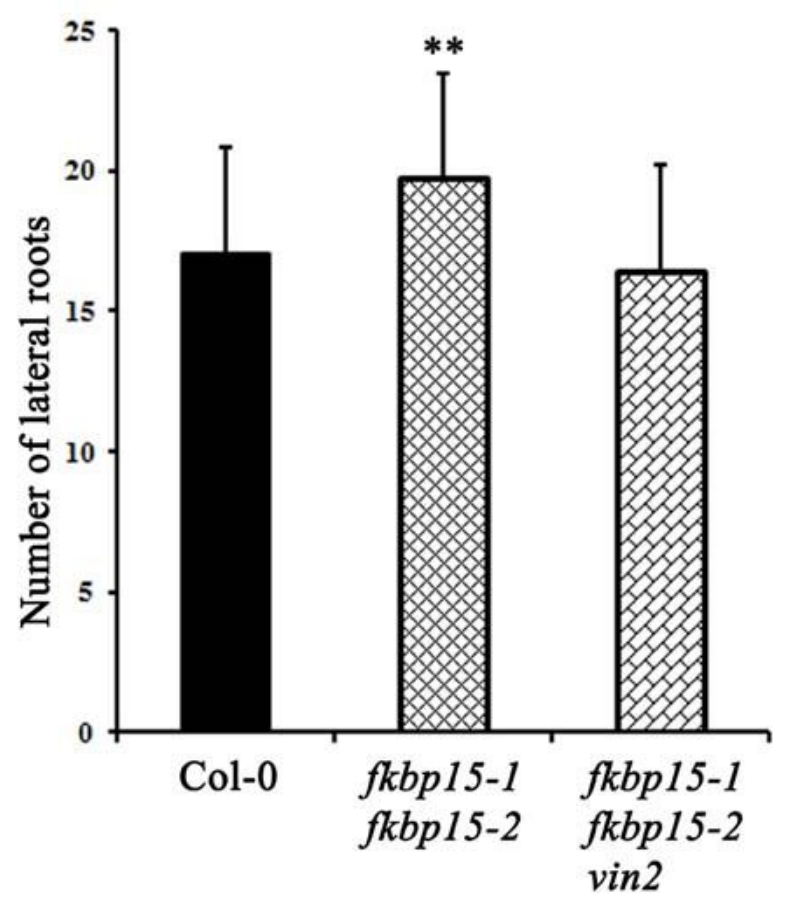

d

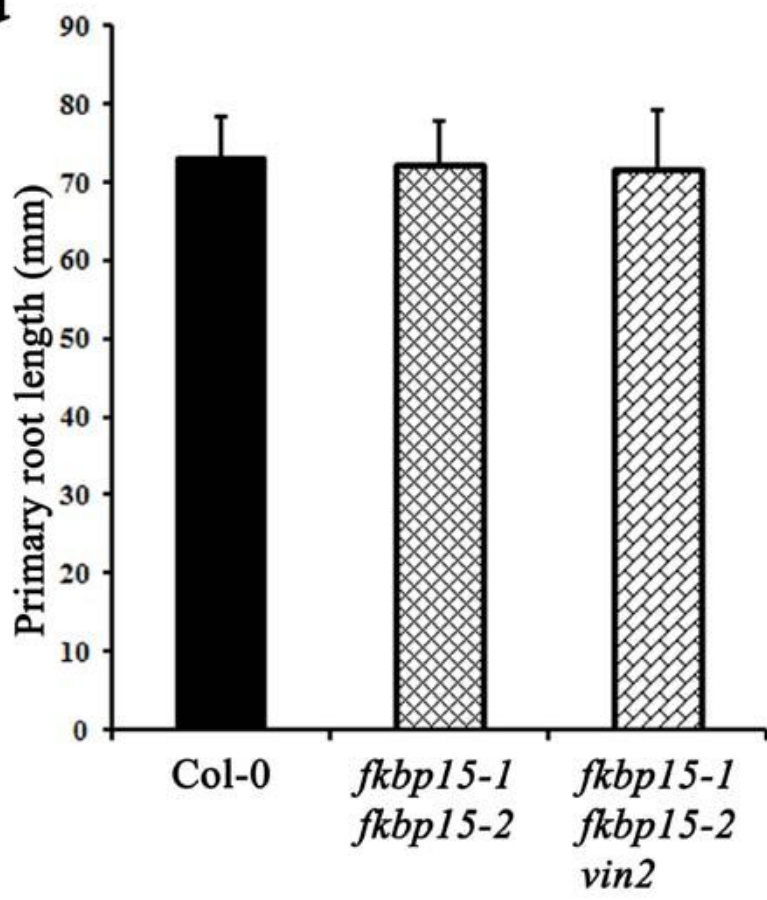

Figure 9

Genetic analysis of FKBP15-1, FKBP15-2 and VIN2. a Phenotypes of 12-day-old Col-0, fkbp15-1fkbp15-2, and fkbp15-1 fkbp15-2vin2 seedlings grown on 0.5x MS medium. Scale bar: $1 \mathrm{~cm}$. b Analysis of lateral root numbers in Col-0, fkbp15-1 fkbp15-2, and fkbp15-1fkbp15-2vin2 seedlings. Bars represent the average values \pm SD of $\geq 30$ seedlings of each genotype. Asterisks indicate significant differences in lateral root number in each genotype compared with Col-0 (*P $\leq 0.05,{ }^{* *} \mathrm{P} \leq 0.01$; Student's t-test). c Fresh 
weights of Col-0, fkbp15-1fkbp15-2, and fkbp15-1fkbp15-2vin2 seedlings. Bars represent the average values $\pm S D$ of $\geq 30$ seedlings of each genotype. Asterisks indicate significant differences in each genotype compared with the Col-0 control ( ${ }^{*} P \leq 0.05,{ }^{*} P \leq 0.01$; Student's t-test). $d$ Primary root lengths in Col-0, fkbp15-1fkbp15-2, and fkbp15-1fkbp15-2vin2 seedlings. Bars represent average values \pm SD of $\geq 30$ seedlings of each genotype. Asterisks indicate significant differences in each genotype compared with Col-0 ( ${ }^{*} \mathrm{P} \leq 0.05,{ }^{*} \mathrm{P} \leq 0.01$; Student's t-test).

\section{Supplementary Files}

This is a list of supplementary files associated with this preprint. Click to download.

- Additionalfile2FigureS2300dpi170mm.tif

- Additionalfile1FigureS1300dpi85mm.tif

- Additionalfile9Table.S2.xlsx

- Additionalfile4FigureS4300dpi170mm.tif

- Additionalfile3FigureS3300dpi85mm.tif

- Additionalfile6FigureS6300dpi170mm.tif

- Additionalfile5FigureS5300dpi170mm.tif

- Additionalfile7FigureS7300dpi170mm.tif

- Additionalfile8Table.S1.xlsx 